\title{
Long non-coding RNA HOTTIP promotes hepatocellular carcinoma tumorigenesis and development: A comprehensive investigation based on bioinformatics, qRT-PCR and meta-analysis of 393 cases
}

\author{
YU ZHANG $^{1 *}$, JIA-CHENG HUANG ${ }^{1 *}$, KAI-TENG CAI ${ }^{1}$, XI-BING YU ${ }^{2}$, YOU-RONG CHEN $^{1}$, \\ WEN-YA PAN ${ }^{1}$, ZE-LIANG HE ${ }^{2}, \mathrm{JUN} \mathrm{LV}^{2}$, ZHEN-BO FENG ${ }^{1}$ and GANG CHEN ${ }^{1}$ \\ Departments of ${ }^{1}$ Pathology and ${ }^{2}$ Hepatobiliary Surgery, First Affiliated Hospital of Guangxi Medical University, \\ Nanning, Guangxi Zhuang Autonomous Region 530021, P.R. China
}

Received June 20, 2017; Accepted October 6, 2017

DOI: $10.3892 /$ ijo.2017.4164

\begin{abstract}
HOTTIP functions as an independent biomarker in multiple cancers. However, the role of HOTTIP in hepatocellular carcinoma (HCC) remains unclear. In this study, we sought to investigate the HOTTIP expression in HCC and normal liver. We combined quantitative reverse transcription-polymerase chain reactions (qRT-PCR), Gene Expression Omnibus (GEO) and The Cancer Genome Atlas (TCGA), Multi Experiment Matrix (MEM) and Oncomine database to assess the clinical role and the potential molecular mechanism of HOTTIP in HCC. Furthermore, a meta-analysis was performed to evaluate the relationship between HOTTIP and HCC tumorigenesis and development. Additionally, bioinformatics analysis, which contained Gene
\end{abstract}

Correspondence to: Dr Zhen-Bo Feng or Dr Gang Chen, Department of Pathology, First Affiliated Hospital of Guangxi Medical University, 6 Shuangyong Road, Nanning, Guangxi Zhuang Autonomous Region 530021, P.R. China

E-mail: fengzhenbo_gxmu@163.com; quanghu 1963"@126.com

E-mail: chen_gang_triones@163.com

${ }^{*}$ Contributed equally

Abbreviations: HCC, hepatocellular carcinoma; qRT-PCR, quantitative reverse transcription-polymerase chain reactions; GEO, Gene Expression Omnibus; TCGA, The Cancer Genome Atlas; MEM, Multi Experiment Matrix; GO, Gene Ontology; KEGG, Kyoto Encyclopedia of Genes and Genomes; lncRNAs, long non-coding RNAs; ROC, receiver operating characteristic; BP, biological process; CC, cellular component; MF, molecular function; DAVID, Database for Annotation, Visualization and Integrated Discovery; NCBI, National Center of Biotechnology Information; mean \pm SD, mean \pm standard deviation; SROC, summary receiver operating characteristic

Key words: HOTTIP, hepatocellular carcinoma, qRT-PCR, GO, KEGG, meta-analysis
Ontology (GO), Kyoto Encyclopedia of Genes and Genomes (KEGG) and network analysis, were applied to investigate the underlying functions, pathways and networks of the potential genes. HOTTIP was obviously upregulated in HCC. A statistically significant higher expression of HOTTIP was found in TNM (III +IV), age ( $\geq 60$ ), sex (male), race (white) and cirrhosis (no) compared to the control groups $(\mathrm{P}<0.05)$. Furthermore, the meta-analysis of 393 cases from multiple centers indicated that HOTTIP had high diagnostic value in HCC. Additionally, according to GO and KEGG analyses, we found that the most strongly enriched functional terms were gland development, transcription factor activity and extrinsic to membrane. Also, the HOTTIP co-expressed genes were significantly related to PPAR signaling pathway. We speculate that HOTTIP might play a vital part in HCC via regulating various pathways, especially PPAR signaling pathway. However, the detailed mechanism should be confirmed by functional experiments.

\section{Introduction}

Hepatocellular carcinoma (HCC) is known as the most common liver malignancy worldwide, with extremely high incidence and mortality rate (1-5). In China, HCC frequently occurs owing to chronic infection of hepatitis $\mathrm{B}$ virus (HBV) (6-9). Other conditions, such as alcoholic hepatitis, non-alcoholic fatty liver disease, hemochromatosis and diabetes, also contribute to the development of HCC (10-12). Up to now, liver transplantation and tumor resection still have been the most effective treatments for HCC, whereas the high metastasis and postoperative recurrence rates barricade the prognosis of HCC patients, especially HCC patients in advanced stage $(13,14)$. As the current treatment options are limited, it is of great significance to investigate the underlying mechanism of $\mathrm{HCC}$, which might provide novel insights into the diagnosis and treatment of HCC patients.

Long non-coding RNAs (IncRNAs) represent the non-protein coding RNAs with the length from 200 nucleotides to $100 \mathrm{~kb}(15-17)$. Recent evidence has clarified that various 
lncRNAs could act as key regulators in disease development, epigenetic gene regulation or transcriptional regulation (18-23). Importantly, lncRNAs can regulate the proliferation, invasion, metastasis and apoptosis of malignancies (24-29). In HCC, growing evidence has demonstrated that the differential expression of lncRNAs could affect the development and progression of HCC by regulating the self-renewal ability of liver cancer stem cells and other biological functions (30-34). Moreover, it has been reported that the lncRNA expression might be also associated with chemotherapy resistance of HCC patients (35-37).

IncRNA HOTTIP, also identified as HOXA-AS6, HOXA13-AS1 and NCRNA00213, is located on 7p15.2, with the NCBI Gene ID: 100316868 (38). Moreover, HOTTIP functions as an independent biomarker in multiple cancers, such as breast cancer and esophageal squamous cell carcinoma (39-42). The high HOTTIP expression could inhibit the growth of glioma, increase the chemoresistance of osteosarcoma and promote tumor invasion of gastric cancer $(33,43,44)$. Although it has been shown that HOTTIP was upregulated in HCC compared with normal tissues and could be related to disease progression and predict the outcome of HCC; nonetheless, the detailed functions and mechanism of HOTTIP in HCC remain elusive (45).

In the present study, we investigated the expression of HOTTIP in HCC and normal liver. Furthermore, we combined Gene Expression Omnibus (GEO) and The Cancer Genome Atlas (TCGA), Multi Experiment Matrix (MEM) and Oncomine database, quantitative reverse transcriptionpolymerase chain reactions (qRT-PCR), and meta-analysis to assess the clinical role and the potential molecular mechanism of HOTTIP in HCC. Additionally, bioinformatics analysis, which contain Gene Ontology (GO), Kyoto Encyclopedia of Genes and Genomes (KEGG) and network analysis, were applied to explore the underlying functions, pathways and networks of the potential genes (46-48). A flow chart of this study is shown in Fig. 1.

\section{Materials and methods}

Quantitative real-time PCR. A total of 41 HCC cases, between January 2012 and March 2013, were collected from the Department of Pathology, First Affiliated Hospital of the Guangxi Medical University (Nanning, Guangxi, China). The samples were collected randomly from patients undergoing surgical resection without treatment. All methods were performed based on the relevant regulations and guidelines. Also, all experimental protocols have been approved by the Ethical Committee of the First Affiliated Hospital of Guangxi Medical University, and the clinicians and patients have signed the consent forms for the use of their tissues in the study. In this study, the total RNA was extracted via a Takara PrimeScript RT reagent kit based on the manufacturer's instructions. Then, the total RNA was used for cDNA synthesis through the Takara PrimeScript RT reagent kit according to the instructions. Then, qRT-PCR was operated using a LightCycler 480 Real-time PCR system (Roche, Shanghai, China). The specific primers were employed as follows: HOTTIP forward, 5'-CACACTCACATTCGCACACT-3'; reverse, 5'-TCCAGAACTAAGCCAGCCATA-3'. GAPDH (internal control) forward,5'-AGTGGCAA AGTGGAGATT-3'; reverse, 5'-GTGGAGTCATACTGGAACA-3' (49). Results were normalized to the GAPDH expression and calculated based on the $\Delta \mathrm{Ct}$ method $(50,51)$.

HOTTIP and HCC: a meta-analysis. HCC-related HOTTIP microarray and RNA-seq datasets were downloaded from TCGA, the National Center of Biotechnology Information (NCBI) GEO (http://www.ncbi.nlm.nih.gov/geo/), ArrayExpress (http://www.ebi.ac.uk/arrayexpress/) and Oncomine (https://www.oncomine.org/resource/main.html). In addition, publications associated with the diagnostic value of HOTTIP in HCC were also selected from 12 online databases: PubMed, Web of Science, Science Direct, Google Scholar, Ovid, LILACS, Wiley Online Library, EMBASE, Cochrane Central Register of Controlled Trials, Chong Qing VIP, Chinese CNKI, Wan Fang and China Biology Medicine disc. The retrieval date was up to April 20, 2017 with the following keywords: (HOTTIP or HOXA-AS6 or HOXA13-AS1 or NCRNA00213) and (malignan* OR cancer OR tumor OR tumor OR neoplas* OR carcinoma) and (hepatocellular OR liver OR hepatic OR HCC). The literature retrieval was assessed and cross-checked by two independent investigators (Jia-Cheng Huang and Wen-Ya Pan). Group discussion was carried out if there was disagreement. The number of true-positives (tp), true-negatives (tn), false-positives (fp) and false-negatives (fn) was extracted. When no direct data was found from a study, a basic formula $($ such as 'sensitivity' $=\mathrm{tp} /(\mathrm{tp}+\mathrm{fn})$, 'specificity' $=\mathrm{tn} /(\mathrm{tn}+\mathrm{fp}))$ would be used to calculate the incidence.

Validation of the expression of HOTTIP in HCC. TCGA (http://cancergenome.nih.gov/) is a collection of SNP arrays, DNA methylation, miRNA-seq, exome sequencing, RNA-seq, and more $(52,53)$. TCGA can be also applied to investigate the complicated cancer genomics expression and clinical parameters. In this study, RNA-Seq data from individuals with $\mathrm{HCC}$, which were calculated on IlluminaHiSeq RNASeq platform, were achieved from TCGA data portal (https://tcga-data.nci.nih.gov/tcga/), containing $171 \mathrm{HCC}$ tissues and 28 adjacent normal liver tissue samples up to April 1, 2017. The expression data of HOTTIP were displayed as reads per million (RPM) and the HOTTIP expression level was normalized by Deseq package of R language for further analysis. Student's t-test (SPSS Inc., Chicago, IL, USA) was performed for the statistical analysis of the differential expression of HOTTIP between HCC and non-cancerous liver tissues. Also, the relationship between HOTTIP and the clinicopathological parameters in HCC was identified based on the original data from TCGA database. Then, the clinical diagnostic value of HOTTIP was analyzed by a receiver operating characteristic (ROC) curve. Furthermore, the original data in Oncomine database was also applied to verify the HOTTIP expression in HCC (54).

The potentialfunctions and pathways associated with HOTTIP. To further investigate the co-expressed genes associated with HOTTIP, MEM (http://biit.cs.ut.ee/mem/index.cgi), an openaccess resource, was utilized to explore the co-expressed genes of HOTTIP based on Affymetrix Gene Chip Human Genome 


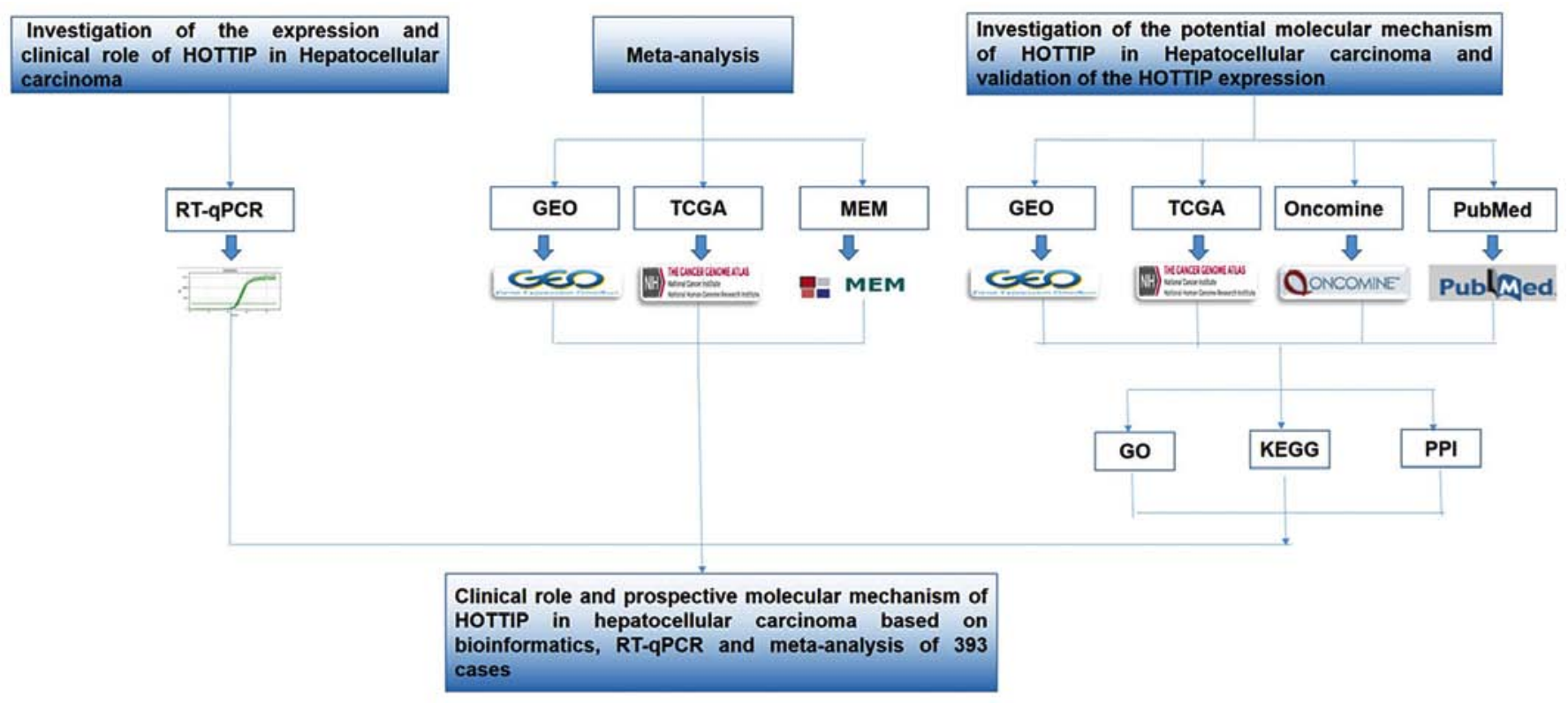

Figure 1. A flow chart of this study.

U133 Plus 2.0 Array platform (55). Differentially expressed genes in TCGA were extracted via $\mathrm{R}$ language package DESeq based on the following criteria: adjusted $\mathrm{P}<0.05$ and the absolute $\log 2$ fold change $>1(56,57)$. Also, the genes differentially expressed in GEO (http://www.ncbi.nlm.nih.gov/geo/) database were selected using the GEO2R online tool (58-61). The overlapping genes were identified and compared using Venn diagrams (available online: http://bioinformatics.psb.ugent.be/ webtools/Venn/). Then, bioinformatics analyses including GO, KEGG and network analysis were applied to explore the potential functions, pathways and networks of the overlapping genes as described $(62,63)$. In this process, Database for Annotation, Visualization and Integrated Discovery (DAVID: available online: http://david.abcc.ncifcrf.gov/) was applied to perform GO and KEGG analyses. In addition, three independent categories [biological process (BP), cellular component (CC) and molecular function (MF)] were derived from $\mathrm{GO}$ analysis. Besides, a functional network was constructed via Cytoscape (version 2.8, http://cytoscape.org).

Construction of protein-protein interaction (PPI) network. The interaction pairs of these co-expressed genes were explored with Search Tool for the Retrieval of Interacting Genes (STRING; version 9.0, http://string-db.org) (64). The STRING database supplies a global perspective for as many organisms as feasible. The known and predicted interactions are integrated and scored. The interaction pairs in PPI network were selected with the combined score $>0.4$.

Statistical analysis. The high-throughput expression data were $\log 2$-transformed. The mean \pm standard deviation (mean \pm SD) was calculated through SPSS 22.0 (IBM, NY, USA) to estimate the HOTTIP expression level in each dataset. The HOTTIP expression between normal liver tissue and HCC was evaluated by Student's t-test. Student's t-test was also used to evaluate the relationships between HOTTIP expression and the clinicopathological parameters. The comparison between subgroups was performed via one-way analysis of variance (ANOVA). A Mann-Whitney U test or Kruskal-Wallis $\mathrm{H}$ test was conducted for non-normally distributed variables. Mining for co-expression genes across hundreds of datasets was carried out via novel rank aggregation and visualization methods. A P-value of $<0.05$ was identified to be statistically significant (two sides) using SPSS 22.0.

In the diagnostic meta-analysis, all the statistical analysis was performed by STATA 14.0 (STATA Corp., College, TX, USA). Heterogeneity between the included studies was assessed by Cochrane's Q test and $\mathrm{I}^{2}$ statistic, and $\mathrm{I}^{2}>50 \%$ represented significant heterogeneity. Publication bias was evaluated by Deek's funnel plot asymmetry test. A P-value of $<0.05$ was regarded significant publication bias. To investigate the underlying diagnostic performance of HOTTIP in $\mathrm{HCC}$, we performed summary receiver operating characteristic (SROC) curves and calculated area under the curve (AUC) with $95 \%$ CIs and the corresponding sensitivity and specificity by using Meta-DISc software (65). An AUC value of 0.5-0.7 was regarded as low diagnostic capability; an AUC of 0.7-0.9 represented a moderate diagnostic ability; an AUC of $>0.9$ indicated a high diagnostic accuracy. We also applied STATA 14.0 (STATA Corp.) to conduct continuous variable meta-analysis. Fixed model (Mantel-Haenszel method) was applied at first and random model (Der Simonian and Laird method) was used when there existed significant heterogeneity. Funnel plot was described to test publication bias.

\section{Results}

The clinical value of HOTTIP expression in HCC. In the present study, an upregulated trend in HOTTIP level in HCC tissues (4.67-fold) was found when compared to normal liver tissues ( $\mathrm{P}=0.002$, Fig. $2 \mathrm{~A}$ ) based on qRT-PCR. We also investigated the relationship between different expression of HOTTIP and clinicopathological parameters. As a result, HOTTIP expression was highly expressed in III +IV and 
Table I. Differential expression of HOTTIP of other clinicopathological parameters in HCC tissue based on qRT-PCR.

\begin{tabular}{|c|c|c|c|c|}
\hline \multirow[b]{2}{*}{ Clinicopathological features } & \multirow[b]{2}{*}{$\mathrm{N}$} & \multicolumn{3}{|c|}{ HOTTIP expression } \\
\hline & & Fold change & $\mathrm{T}$ & P-value \\
\hline \multicolumn{5}{|l|}{ Tissues } \\
\hline Normal liver & 41 & 1.00 & 3.226 & 0.002 \\
\hline $\mathrm{HCC}$ & 41 & 4.67 & & \\
\hline \multicolumn{5}{|l|}{ Age } \\
\hline$<50$ & 19 & 3.33 & 1.233 & 0.226 \\
\hline$\geq 50$ & 22 & 6.00 & & \\
\hline \multicolumn{5}{|l|}{$\operatorname{Sex}$} \\
\hline Male & 31 & 5.17 & 0.775 & 0.443 \\
\hline Female & 10 & 3.17 & & \\
\hline \multicolumn{5}{|l|}{ Cirrhosis } \\
\hline No & 27 & 6.00 & -2.212 & 0.035 \\
\hline Yes & 14 & 2.17 & & \\
\hline \multicolumn{5}{|l|}{ TNM } \\
\hline $\mathrm{I}+\mathrm{II}$ & 25 & 2.50 & -2.255 & 0.037 \\
\hline $\mathrm{III}+\mathrm{IV}$ & 16 & 8.17 & & \\
\hline \multicolumn{5}{|l|}{ Metastasis } \\
\hline No & 38 & 4.17 & -0.754 & 0.528 \\
\hline Yes & 3 & 10.83 & & \\
\hline \multicolumn{5}{|l|}{ Tumor diameter $(\mathrm{cm})$} \\
\hline$<7$ & 11 & 2.67 & -1.126 & 0.267 \\
\hline$\geq 7$ & 30 & 5.50 & & \\
\hline \multicolumn{5}{|l|}{ Vascular invasion } \\
\hline No & 35 & 5.00 & 0.772 & 0.445 \\
\hline Yes & 6 & 2.67 & & \\
\hline \multicolumn{5}{|l|}{ Complete capsule } \\
\hline No & 16 & 4.67 & 0.050 & 0.961 \\
\hline Yes & 25 & 4.83 & & \\
\hline \multicolumn{5}{|l|}{ Differentiation } \\
\hline Low & 10 & 3.17 & $\mathrm{~F}=2.194$ & 0.125 \\
\hline Moderate & 27 & 4.67 & & \\
\hline High & 4 & 8.33 & & \\
\hline \multicolumn{5}{|l|}{ AFP } \\
\hline Negative & 22 & 5.50 & -1.409 & 0.169 \\
\hline Positive & 13 & 2.67 & & \\
\hline \multicolumn{5}{|l|}{ Embolus } \\
\hline No & 39 & 4.83 & 0.791 & 0.433 \\
\hline Yes & 2 & 0.83 & & \\
\hline
\end{tabular}

no cirrhosis groups $(\mathrm{P}<0.05$, Table I and Fig. 2B and $\mathrm{C})$ in HCC, but no statistical significance was found in other clinicopathological parameters. In addition, the diagnostic value of the HOTTIP level in HCC was assessed by a ROC curve and the AUC of HOTTIP was 0.762 (95\% CI, 0.660-0.864, P-value of $<0.001$, Fig. 2D), indicating a moderate diagnostic value of the HOTTIP level in HCC.
HOTTIP and HCC: a meta-analysis. The meta-analysis included 393 cases from multiple centers [two datasets in GEO (GSE58043 and GSE51701), the original data in TCGA, two probe sets (1564069_at and 1564070_s_at) of Wurmbach Liver in Oncomine and one publication (45)]. Thus, the pooled sensitivity and specificity of HOTTIP was 0.88 (0.70-0.96) and 0.59 (0.20-0.89, Fig. 3), respectively. In addition, the 

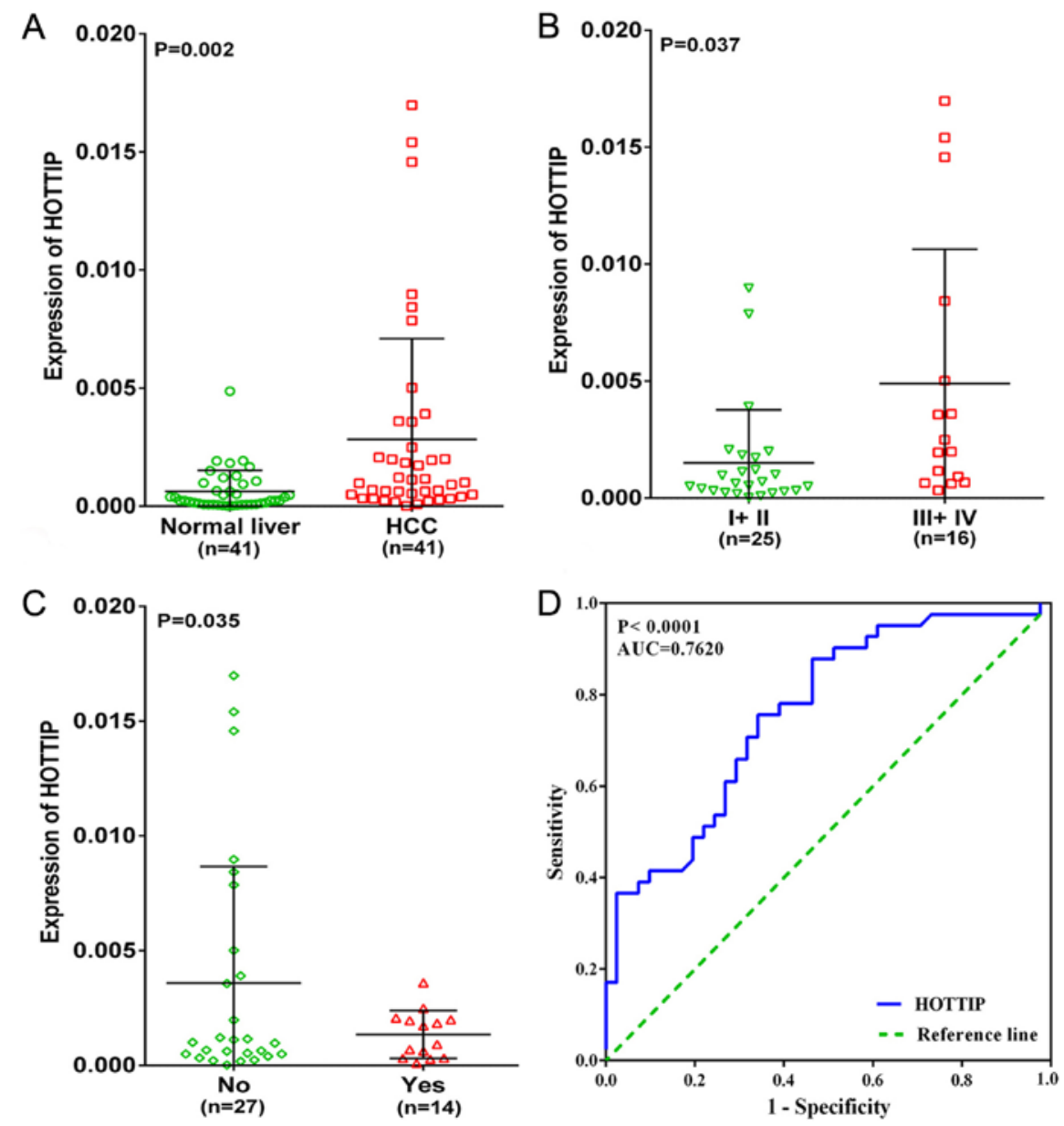

Figure 2. Clinical significance of HOTTIP in HCC based on qRT-PCR. (A) Differential expression of HOTTIP between HCC and non-cancerous liver tissue. (B) Differential expression of HOTTIP in I+ II vs. III +IV. (C) With cirrhosis vs. without cirrhosis. (D) ROC curve of HOTTIP in HCC.
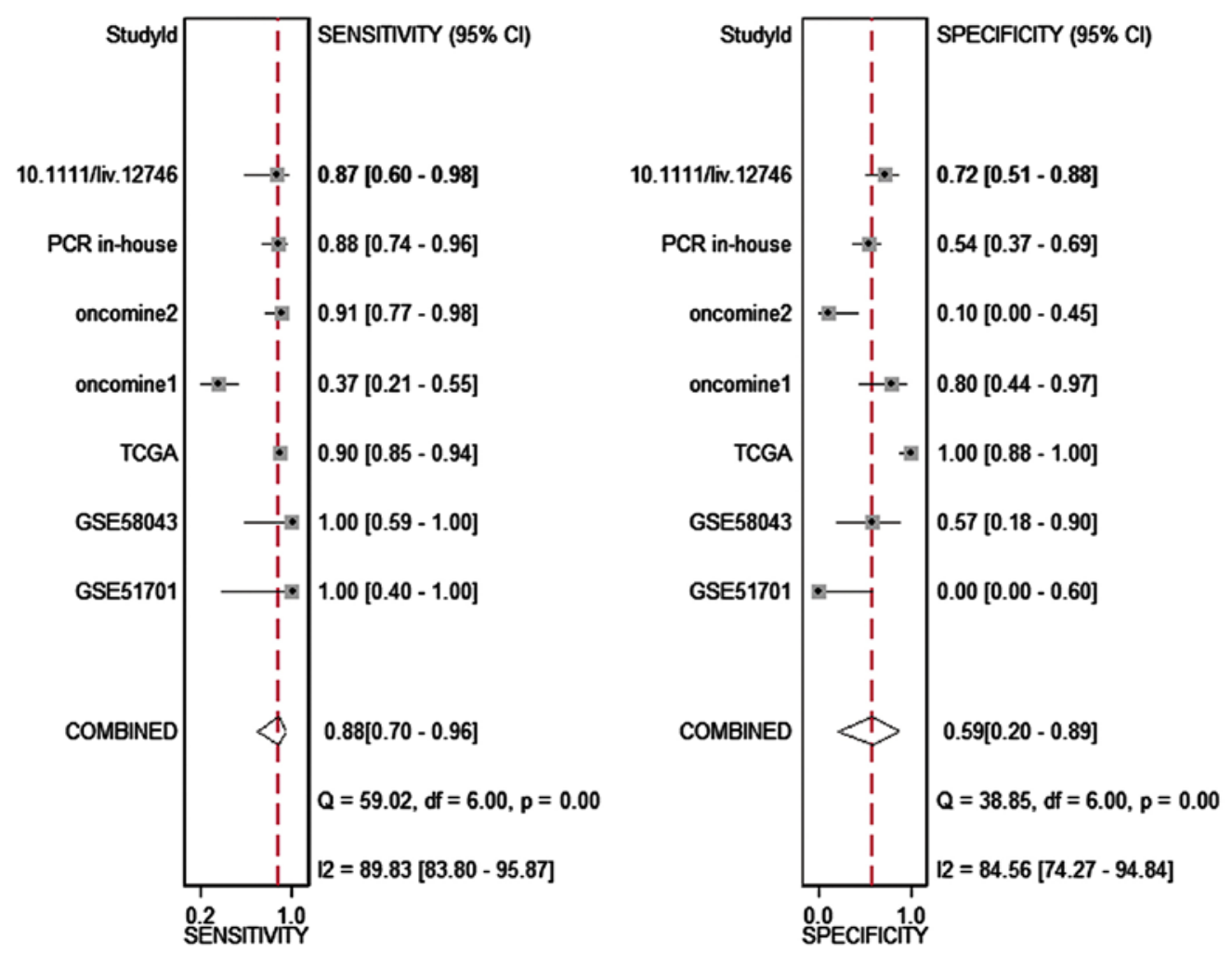

Figure 3. Forest plot showing the pooled sensitivity and specificity of the included studies. The pooled sensitivity and specificity of HOTTIP was 0.88 ( $0.70-0.96)$ and $0.59(0.20-0.89)$, respectively. 

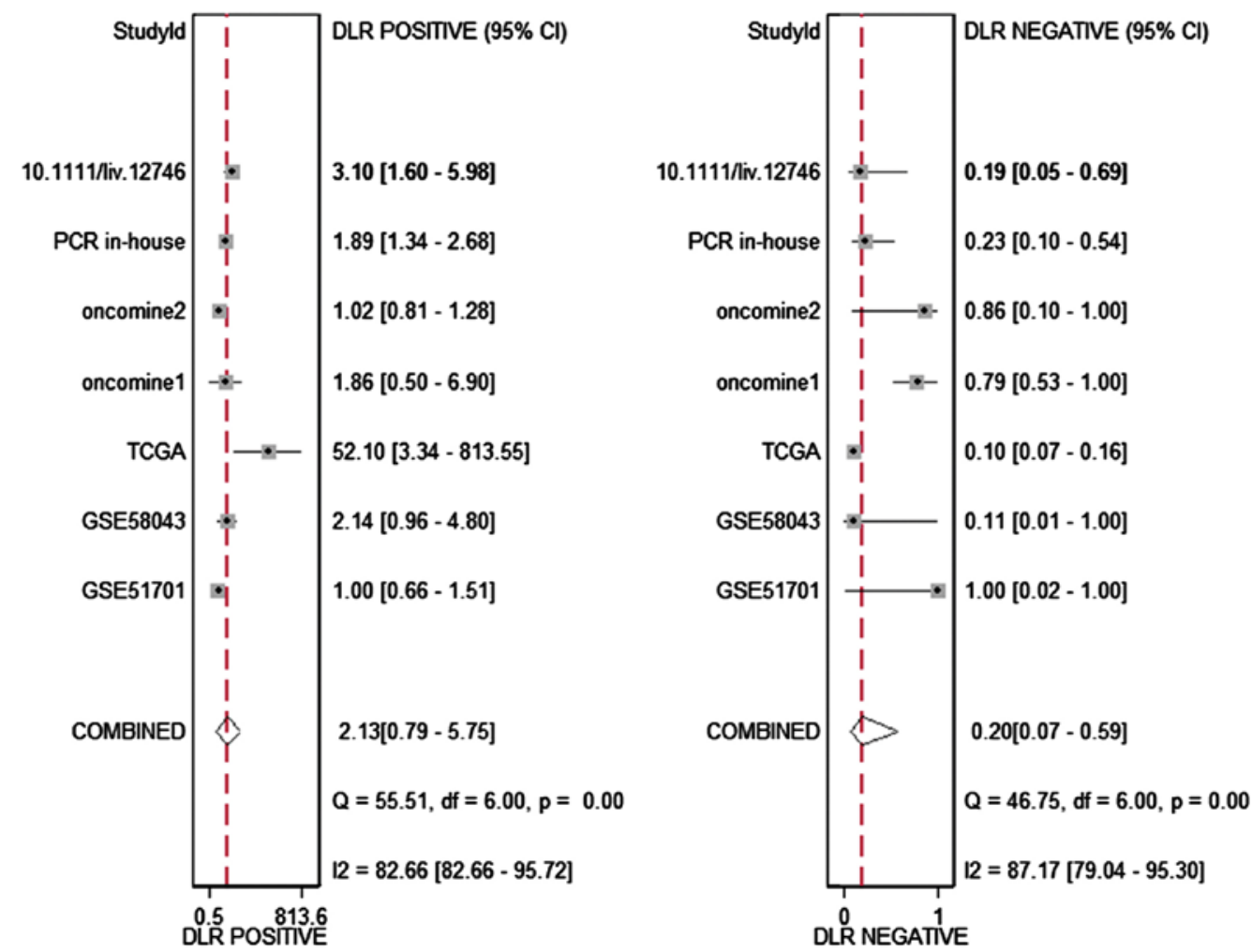

Figure 4. Forest plot showing the pooled positive DLR and negative DLR of the included studies. In addition, the DLR-positive and DLR-negative was $2.13(0.79-5.75)$ and $0.20(0.07-0.59)$, respectively.
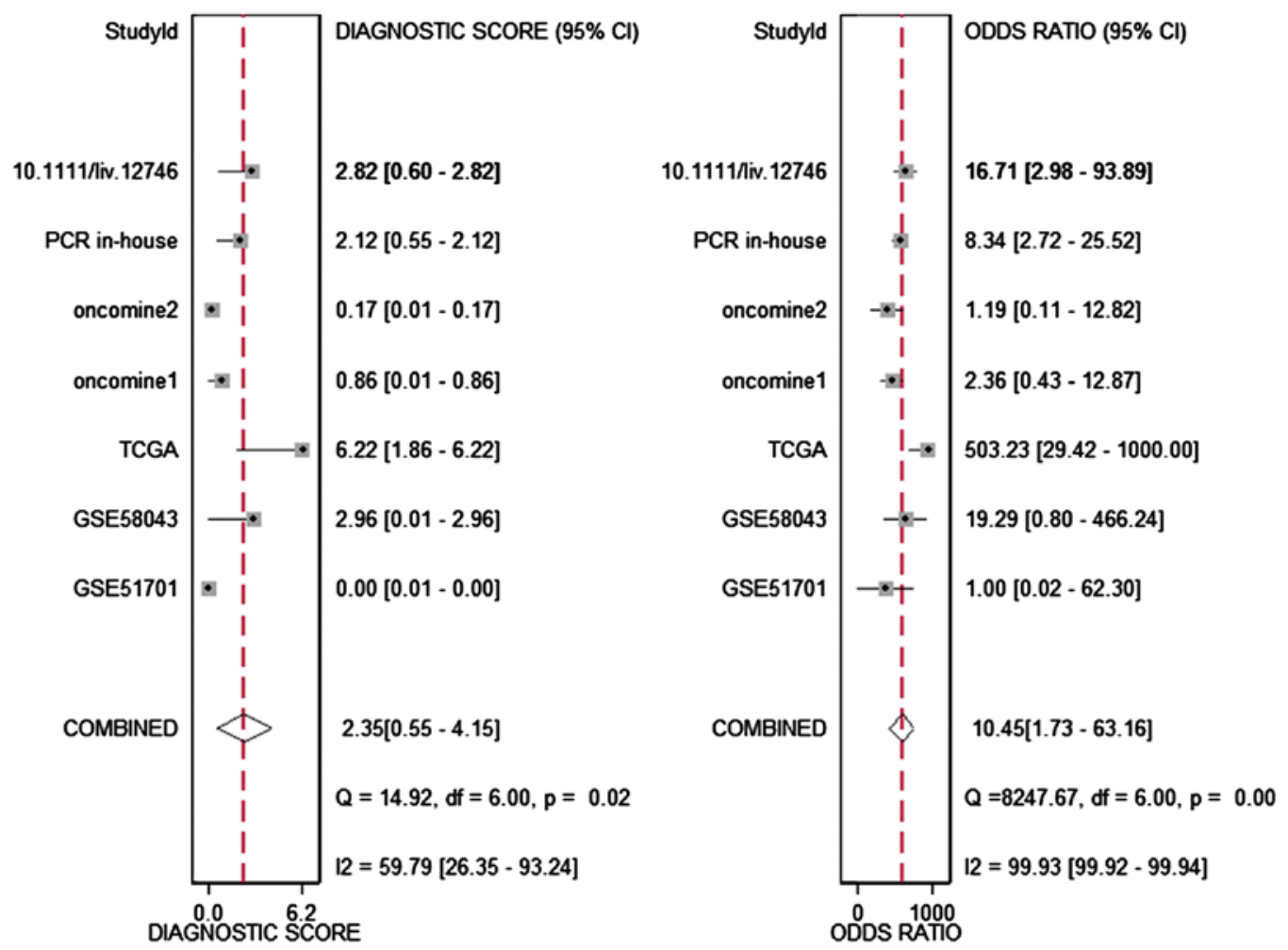

Figure 5. Forest plot showing the pooled diagnostic score and diagnostic odds ratio of the included studies. The diagnostic score and odds ratio was $2.35(0.55-4.15)$ and $10.45(1.73-63.16)$, respectively.

DLR-positive and DLR-negative were $2.13(0.79-5.75)$ and $0.20(0.07-0.59$, Fig. 4$)$, respectively. The diagnostic score and odds ratio were 2.35 (0.55-4.15) and 10.45 (1.73-63.16, Fig. 5), respectively. The AUC of SROC was 0.87 (0.83-0.89, Fig. 6), which indicated a moderate diagnostic value of HOTTIP in HCC. The pre-test probability was $20 \%$ when the positive and 


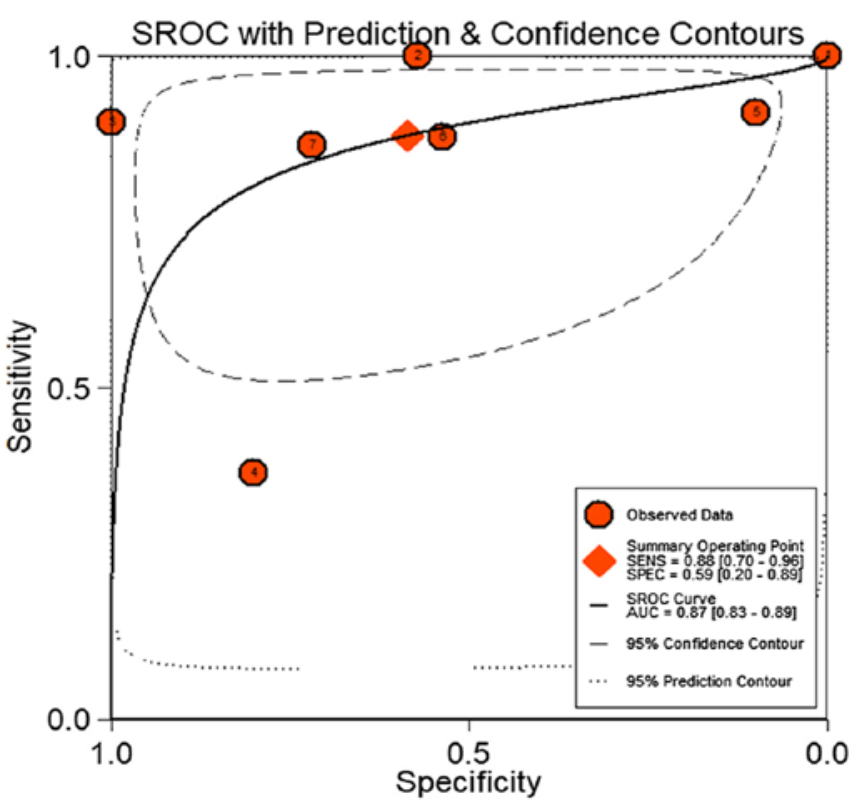

Figure 6. The summary receiver operating characteristic (SROC) curve for assessment of the diagnostic accuracy of HOTTIP for HCC. The AUC of SROC was 0.87 (0.83-0.89), which indicated a moderate diagnostic value of HOTTIP in HCC.

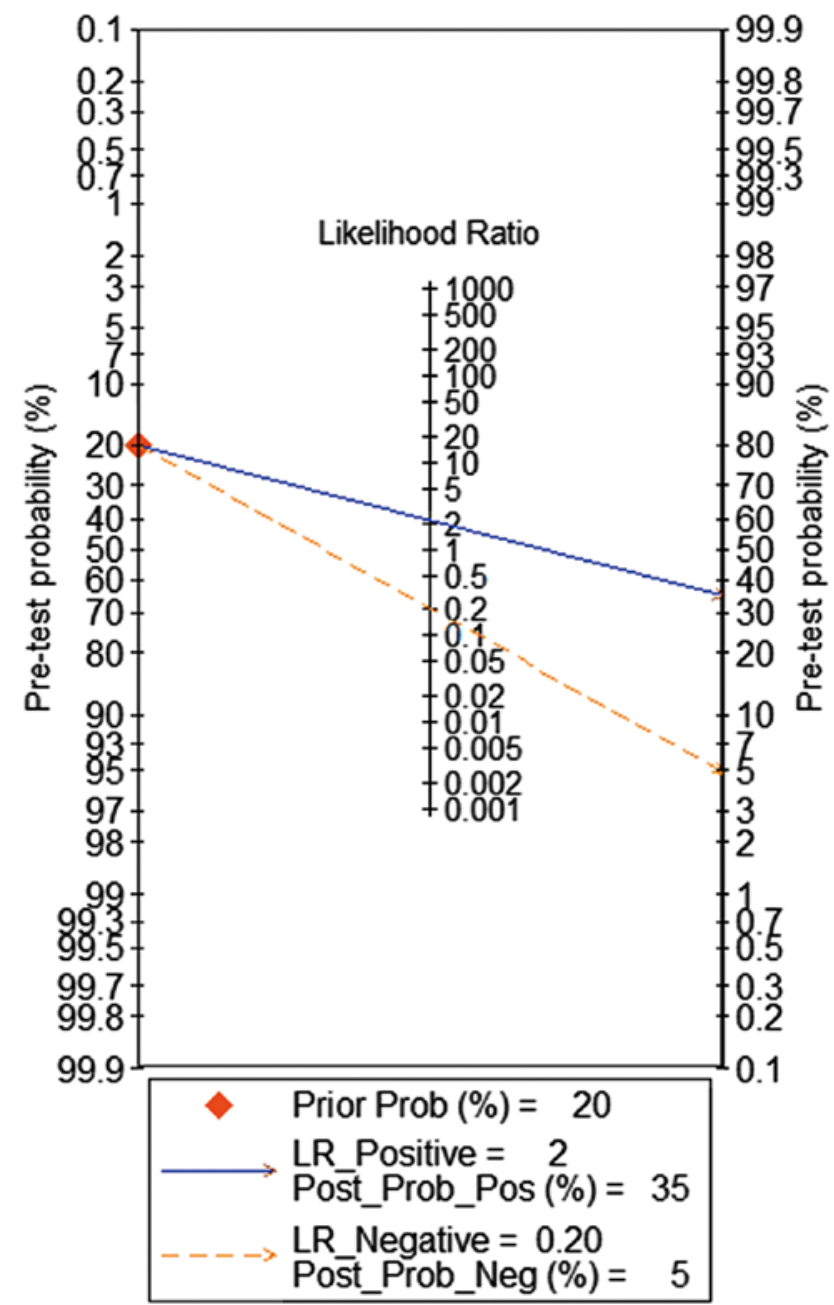

Figure 7. The pre-test and post-test probability of the included studies. The pretest probability was $20 \%$ when the positive and negative pre-test probability was 35 and 5\%, respectively.

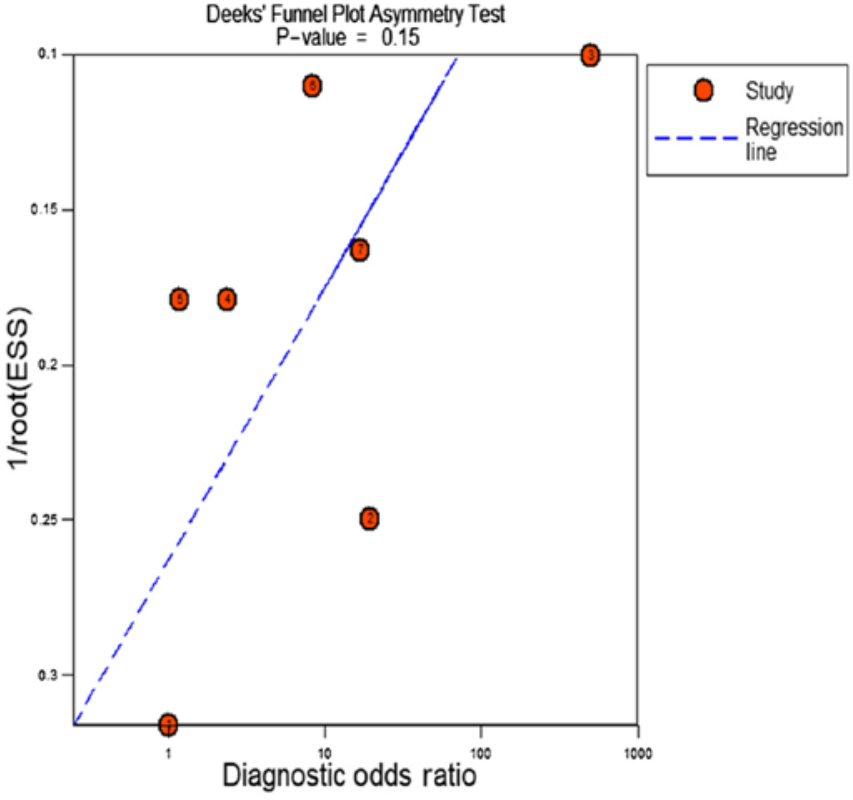

Figure 8. Publication bias of the included studies. 1/root (ESS) meant inverse root of effective sample sizes. Each circle represented an included study.

negative pre-test probability was 35 and 5\% (Fig. 7), respectively. As for the publication bias, no significant publication bias was found ( $\mathrm{P}=0.15$, Fig. 8).

As for the expression of HOTTIP in HCC compared to non-cancerous group, a fix-effect model was selected to calculate the pooled standard mean deviation (SMD) and 95\% CI and the combined SMD reached $0.83(0.57,1.09)$, indicating a statistically significant higher expression of HOTTIP could be found in HCC than in normal control groups $(\mathrm{P}<0.001$, Fig. 9A). In addition, no report bias was found in our study ( $P>0.05$, Fig. 9B). Above all, a flow chart of this meta-analysis is shown in Fig. 10.

Validation of the expression of HOTTIP in HCC. To further explore the differential expression of HOTTIP between HCC and non-cancerous liver tissues, we performed a clinical research based on the original data in TCGA. One HCC cohort, which was comprised of $171 \mathrm{HCC}$ cases and 28 non-cancerous liver cases, was extracted. Increased expression of HOTTIP was observed in HCC tissues (5.001 \pm 2.453$)$ compared with the non-cancerous tissues $(0.182 \pm 0.459, \mathrm{P}<0.001$, Fig. $11 \mathrm{~A})$. With regard to the clinicopathological parameters, we found that HOTTIP expression was highly expressed in age $(\geq 60)$, sex (male), race (white) compared to that in the control group (P-value of $<0.05$, Table II and Fig. 11B-D). For the other clinicopathological characteristics, no statistical significance was found based on TCGA database. Moreover, the AUC of HOTTIP reached 0.982 (95\% CI, 0.966-0.998, $\mathrm{P}<0.0001$, Fig. 11E), which indicated a high diagnostic value of the HOTTIP level in HCC.

Additionally, two probe sets (1564069_at and 1564070_s_at) of Wurmbach Liver in Oncomine were used to validate the HOTTIP expression. However, an opposite trend was found in the two probe sets (Fig. 12). HOTTIP was downregulated in 1564070_s_at probe set compared to the normal liver, which was inconsistent with the results of qRT-PCR and TCGA. 

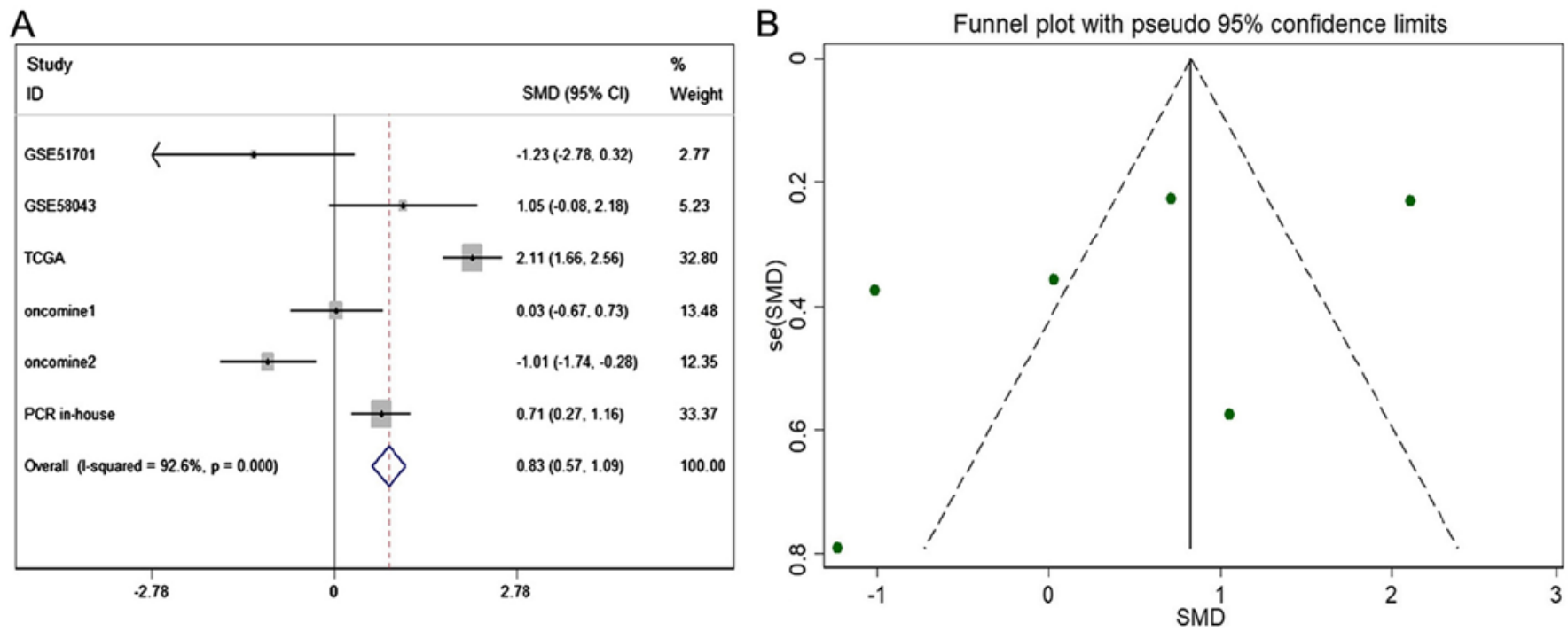

Figure 9. The expression condition of HOTTIP in HCC compared to non-cancerous. (A) Forest plot of datasets evaluating HOTTIP expression between HCC and normal control groups (random-effects model). (B) Funnel plot of datasets and no publication bias was found in our study.

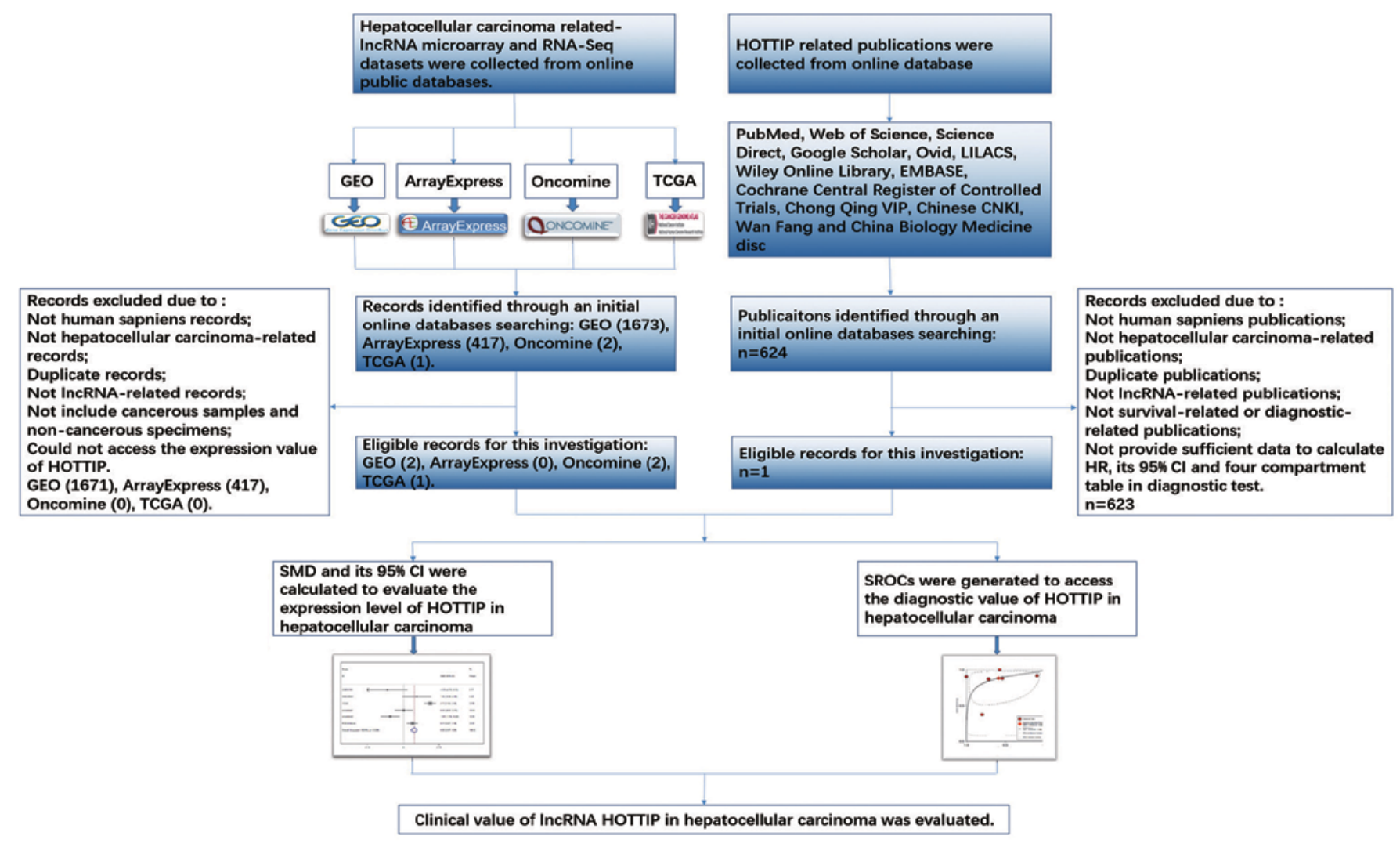

Figure 10. A flow chart of this meta-analysis.

Also, the opposite trend of HOTTIP expression might be a source of heterogeneity in meta-analysis.

The potential pathways associated with HOTTIP. Based on GEO, TCGA and MEM database, 287 overlapped genes were selected (Fig. 13). In addition, GO and pathway analyses were performed using these 287 genes. The most strongly enriched GO terms were identified as follows: embryonic morphogenesis, gland development, transcription factor activity and extrinsic to membrane (Table III). To better affect the functions of these genes, a function network was constructed according to GO analysis (Fig. 14). Besides, the KEGG pathway analysis confirmed that these genes were significantly involved in PPAR signaling pathway, Fc $\gamma$ R-mediated phagocytosis and endocytosis (Table IV). Altogether, the GO and KEGG pathway analysis revealed that HOTTIP might participate in the biological mechanism of HCC. In addition, a gene network of the 287 genes was 

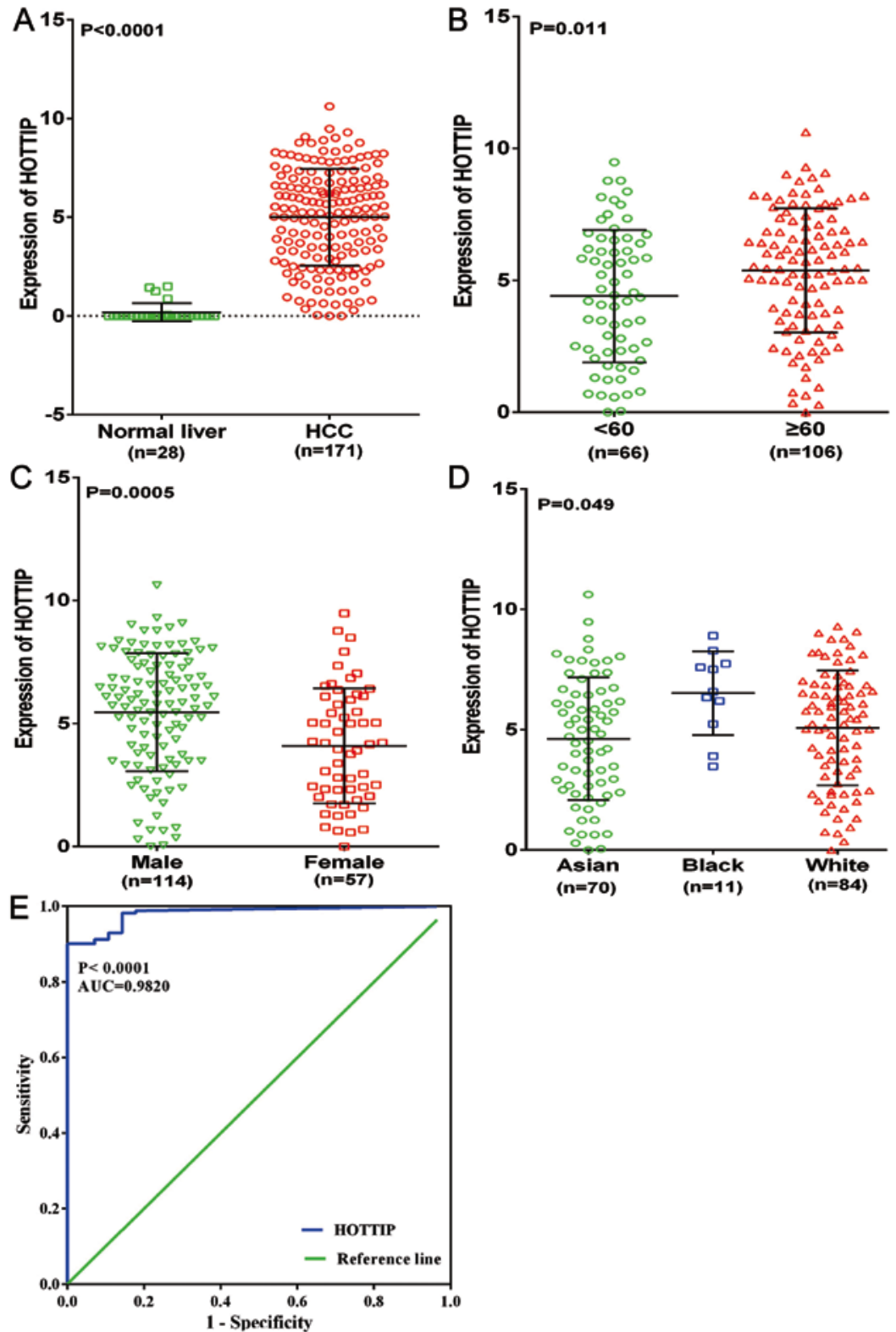

$(\mathbf{n = 7 0})$

(n=11)

$(n=84)$

Figure 11. Clinical significance of HOTTIP in HCC based on TCGA database. (A) Differential expression of HOTTIP between HCC and non-cancerous liver tissue. (B) Differential expression of HOTTIP in $<60$ vs. $\geq 60$. (C) Male vs female. (D) Asian vs. Black vs. White. (E) ROC curve of HOTTIP in HCC.
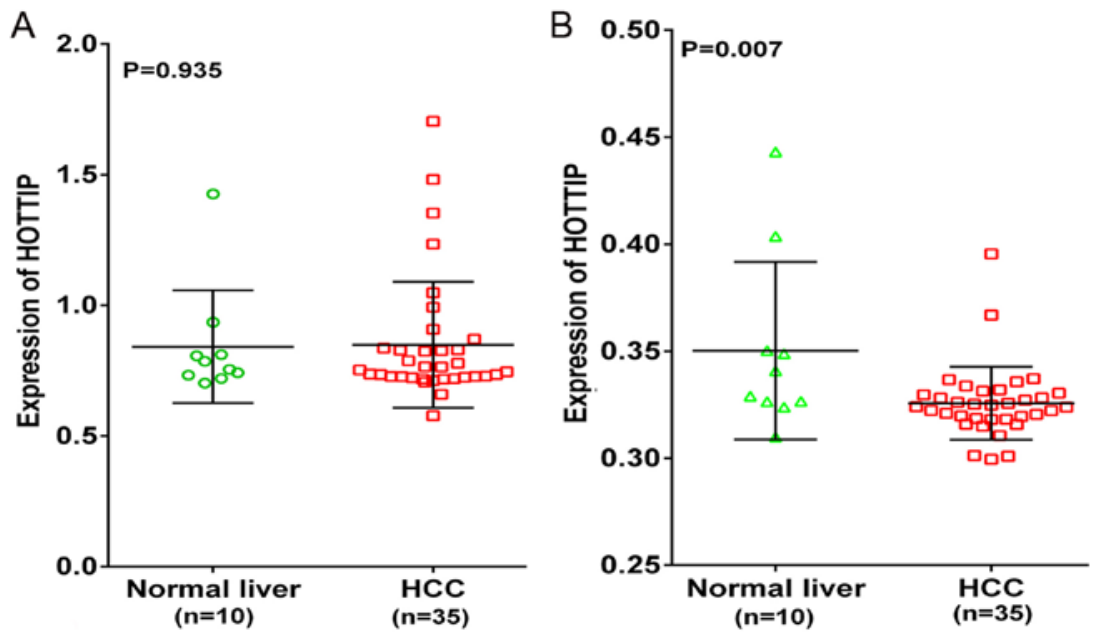

Figure 12. Validation of HOTTIP expression in the cohort of Wurmbach Liver from Oncomine. (A) Normal liver tissues ( $\mathrm{n}=10$ ) and hepatocellular carcinoma tissues $(\mathrm{n}=35)$ were included in the cohort of Wurmbach Liver (1564069_at). (B) Normal liver tissues $(\mathrm{n}=10)$ and hepatocellular carcinoma tissues $(\mathrm{n}=35)$ were included in the cohort of Wurmbach Liver (1564070_s_at). 
Table II. Differential expression of HOTTIP of clinicopathological parameters in HCC tissue based on TCGA database.

\begin{tabular}{|c|c|c|c|c|}
\hline \multirow[b]{2}{*}{ Clinicopathological features } & \multirow[b]{2}{*}{$\mathrm{N}$} & \multicolumn{3}{|c|}{ HOTTIP expression } \\
\hline & & Mean \pm SD & $\mathrm{T}$ & P-value \\
\hline \multicolumn{5}{|l|}{ Tissues } \\
\hline Normal liver & 28 & $0.182 \pm 0.459$ & \multirow[t]{2}{*}{8.16} & \multirow[t]{2}{*}{$<0.0001$} \\
\hline $\mathrm{HCC}$ & 171 & $5.001 \pm 2.453$ & & \\
\hline \multicolumn{5}{|l|}{ Age } \\
\hline$<60$ & 66 & $4.405 \pm 2.513$ & \multirow[t]{2}{*}{-2.563} & \multirow[t]{2}{*}{0.011} \\
\hline$\geq 60$ & 106 & $5.376 \pm 2.349$ & & \\
\hline \multicolumn{5}{|l|}{ Sex } \\
\hline Male & 114 & $5.457 \pm 2.393$ & \multirow[t]{2}{*}{3.556} & \multirow[t]{2}{*}{0.0005} \\
\hline Female & 57 & $4.089 \pm 2.332$ & & \\
\hline \multicolumn{5}{|l|}{ Race } \\
\hline White & 84 & $5.077 \pm 2.379$ & \multirow[t]{3}{*}{$\mathrm{F}=3.078$} & \multirow[t]{3}{*}{0.049} \\
\hline Black & 11 & $6.522 \pm 1.740$ & & \\
\hline Yellow & 70 & $4.622 \pm 2.540$ & & \\
\hline \multicolumn{5}{|l|}{$\mathrm{T}$ (tumor) } \\
\hline $\mathrm{T} 1+\mathrm{T} 2$ & 133 & $5.099 \pm 2.372$ & \multirow[t]{2}{*}{1.236} & \multirow[t]{2}{*}{0.218} \\
\hline T3+ T4 & 37 & $4.539 \pm 2.657$ & & \\
\hline \multicolumn{5}{|l|}{ Vascular invasion } \\
\hline No & 95 & $4.898 \pm 2.405$ & \multirow[t]{2}{*}{0.521} & \multirow[t]{2}{*}{0.603} \\
\hline Yes & 51 & $5.118 \pm 2.509$ & & \\
\hline \multicolumn{5}{|l|}{ Patological grade } \\
\hline $\mathrm{g} 1+\mathrm{g} 2$ & 107 & $5.068 \pm .2 .434$ & \multirow[t]{2}{*}{0.569} & \multirow[t]{2}{*}{0.570} \\
\hline $\mathrm{g} 3+\mathrm{g} 4$ & 61 & $4.847 \pm 2.382$ & & \\
\hline \multicolumn{5}{|l|}{ Stage } \\
\hline I+ II & 126 & $5.065 \pm 2.333$ & \multirow[t]{2}{*}{1.544} & \multirow[t]{2}{*}{0.125} \\
\hline $\mathrm{III}+\mathrm{IV}$ & 32 & $4.341 \pm 2.520$ & & \\
\hline \multicolumn{5}{|l|}{ Recurrence } \\
\hline No & 151 & $4.942 \pm 2.468$ & \multirow{2}{*}{1.334} & \multirow[t]{2}{*}{0.184} \\
\hline Yes & 10 & $6.008 \pm 2.029$ & & \\
\hline
\end{tabular}

Table III. Top 5 enrichment GO terms (BP, CC and MF) of the potential genes of HOTTIP.

\begin{tabular}{llccr}
\hline GO ID & \multicolumn{1}{c}{ Term } & Ontology & Count & P-value \\
\hline GO:0048732 & Gland development & BP & 12 & $5.32 \mathrm{E}-06$ \\
GO:0007389 & Pattern specification process & BP & 16 & $1.08 \mathrm{E}-05$ \\
GO:0003002 & Regionalization & BP & 13 & $3.84 \mathrm{E}-05$ \\
GO:0048598 & Embryonic morphogenesis & BP & 16 & $5.50 \mathrm{E}-05$ \\
GO:0051216 & Cartilage development & BP & 8 & $1.12 \mathrm{E}-04$ \\
GO:0043565 & Sequence-specific DNA binding & MF & 23 & $3.61 \mathrm{E}-04$ \\
GO:0003700 & Transcription factor activity & MF & 31 & $5.20 \mathrm{E}-04$ \\
GO:0008289 & Lipid binding & MF & 17 & $2.81 \mathrm{E}-03$ \\
GO:0004385 & Guanylate kinase activity & MF & 3 & $1.31 \mathrm{E}-02$ \\
GO:0042803 & Protein homodimerization activity & MF & 12 & $2.08 \mathrm{E}-02$ \\
GO:0019898 & Extrinsic to membrane & CC & 23 & $3.54 \mathrm{E}-06$ \\
GO:0045177 & Apical part of cell & CC & 13 & $1.32 \mathrm{E}-05$ \\
GO:0016324 & Apical plasma membrane & CC & 11 & $2.63 \mathrm{E}-05$ \\
GO:0044459 & Plasma membrane part & CC & 52 & $4.28 \mathrm{E}-04$ \\
GO:0005624 & Membrane fraction & CC & 22 & $7.97 \mathrm{E}-03$ \\
\hline
\end{tabular}

GO, Gene Ontology. BP, biological process. CC, cellular component. MF, molecular function. 


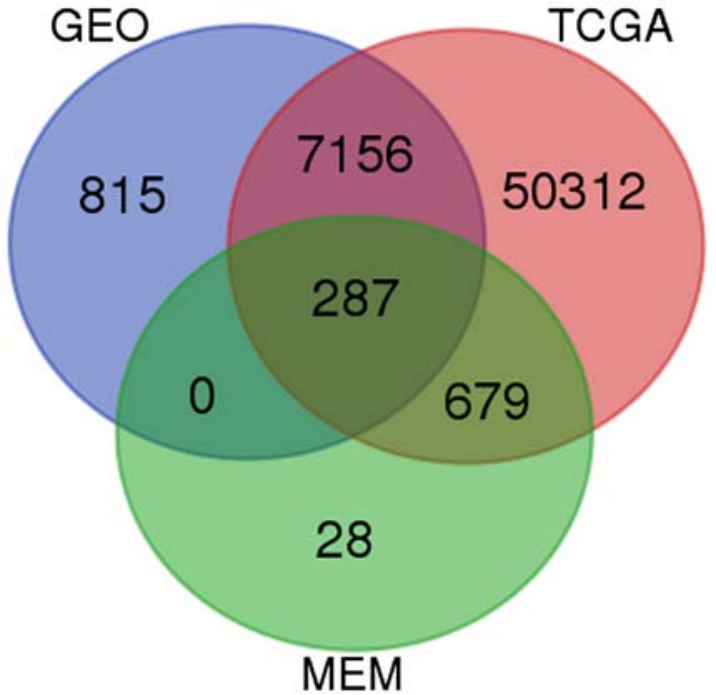

Figure 13. A flow chart to screen the co-expressed genes based on Venn diagrams. constructed in the present study (Fig. 15), from which we could easily observe relationships between HOTTIP and these potential genes.

The PPI network was constructed through STRING online and a total of 72 PPI pairs with combined score $>0.4$ were noted (Fig. 16). Also, PPARA had the highest degree (degree 6) according to the PPI network.

In addition, a total of four genes (PPARA, PPARG, FABP2, SCP2) related to PPAR signaling pathway were detected based on KEGG pathway analysis. Moreover, we investigated the expression of these four genes and their correlations with HOTTIP based on the original data in TCGA. We found that both PPARG and FABP2 were highly expressed in HCC compared to normal liver $(\mathrm{P}<0.05$, Fig. 17A and B), whereas SCP2 was highly expressed in normal liver $(14.99 \pm 0.082$ vs. $13.74 \pm 0.064, \mathrm{P}<0.001$, Fig. 17C). However, only a minor difference was found in PPARA expression between normal liver and HCC $(11.88 \pm 0.098$ vs. $11.73 \pm 0.054$, $\mathrm{P}=0.174$, Fig. 17D). As for the correlation between HOTTIP

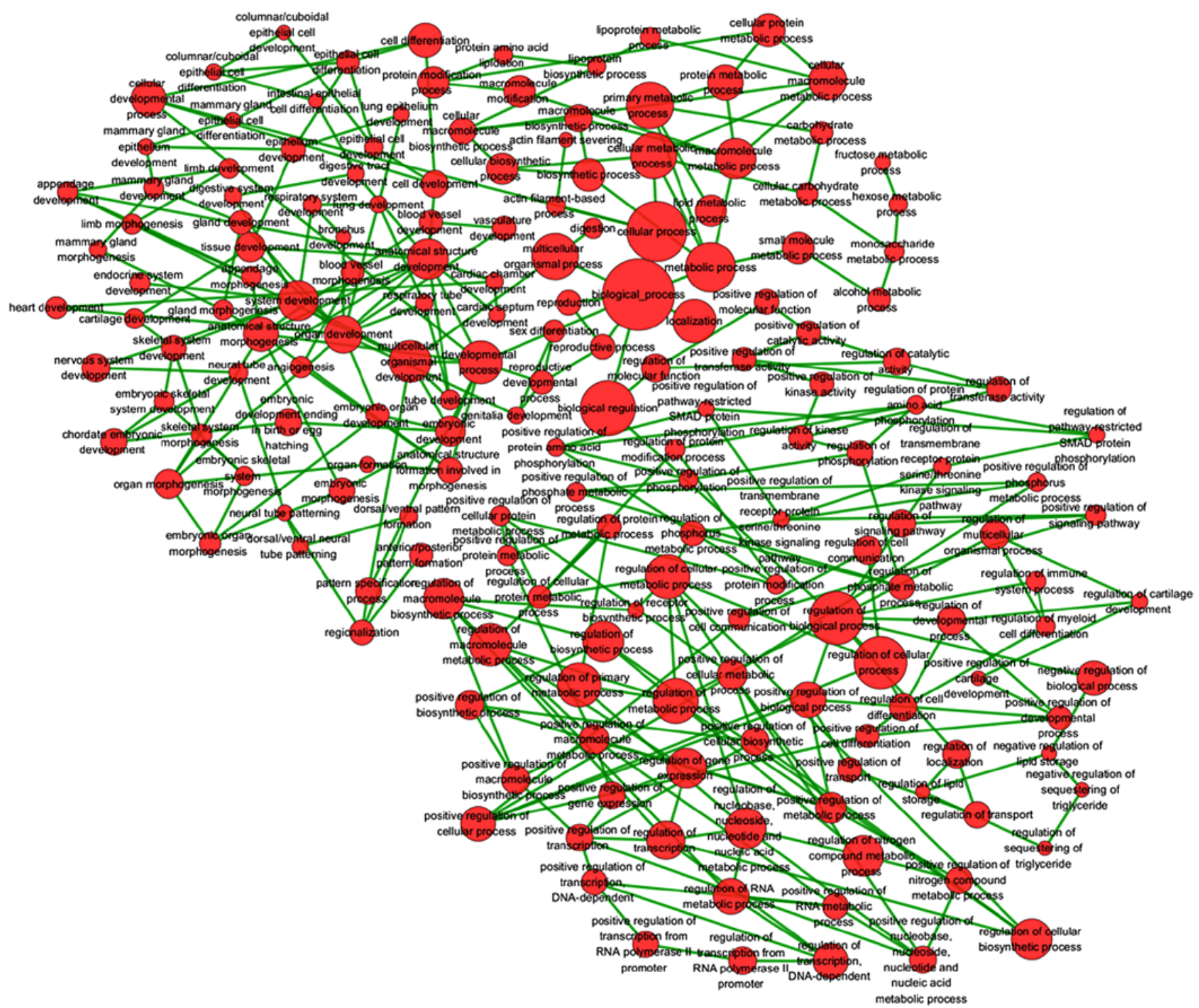

Figure 14. A function network of Gene Ontology (GO) terms for the potential genes of HOTTIP in HCC. Based on GEO, TCGA and MEM database, 287 overlapped genes were selected. In addition, GO analysis was performed using these 287 genes. To further reflect the functions of these genes, a function network was constructed based on GO analysis. 
Table IV. KEGG pathway enrichment analysis of the potential genes of HOTTIP.

\begin{tabular}{llcll} 
KEGG ID & \multicolumn{1}{c}{ KEGG term } & Count & P-value & Gene symbol \\
\hline hsa04666 & Fc $\gamma$ R-mediated phagocytosis & 5 & $5.94 \mathrm{E}-02$ & VAV3, SCIN, PIP5K1B, PLA2G4F, SYK \\
hsa04144 & Endocytosis & 7 & $6.52 \mathrm{E}-02$ & ACVR1B, EPN3, CHMP4C, ERBB3, RAB4A, \\
& & & & PIP5K1B, NEDD4L \\
hsa03320 & PPAR signaling pathway & 4 & $9.13 \mathrm{E}-02$ & PPARA, PPARG, FABP2, SCP2 \\
\hline
\end{tabular}

KEGG, Kyoto Encyclopedia of Genes and Genomes.

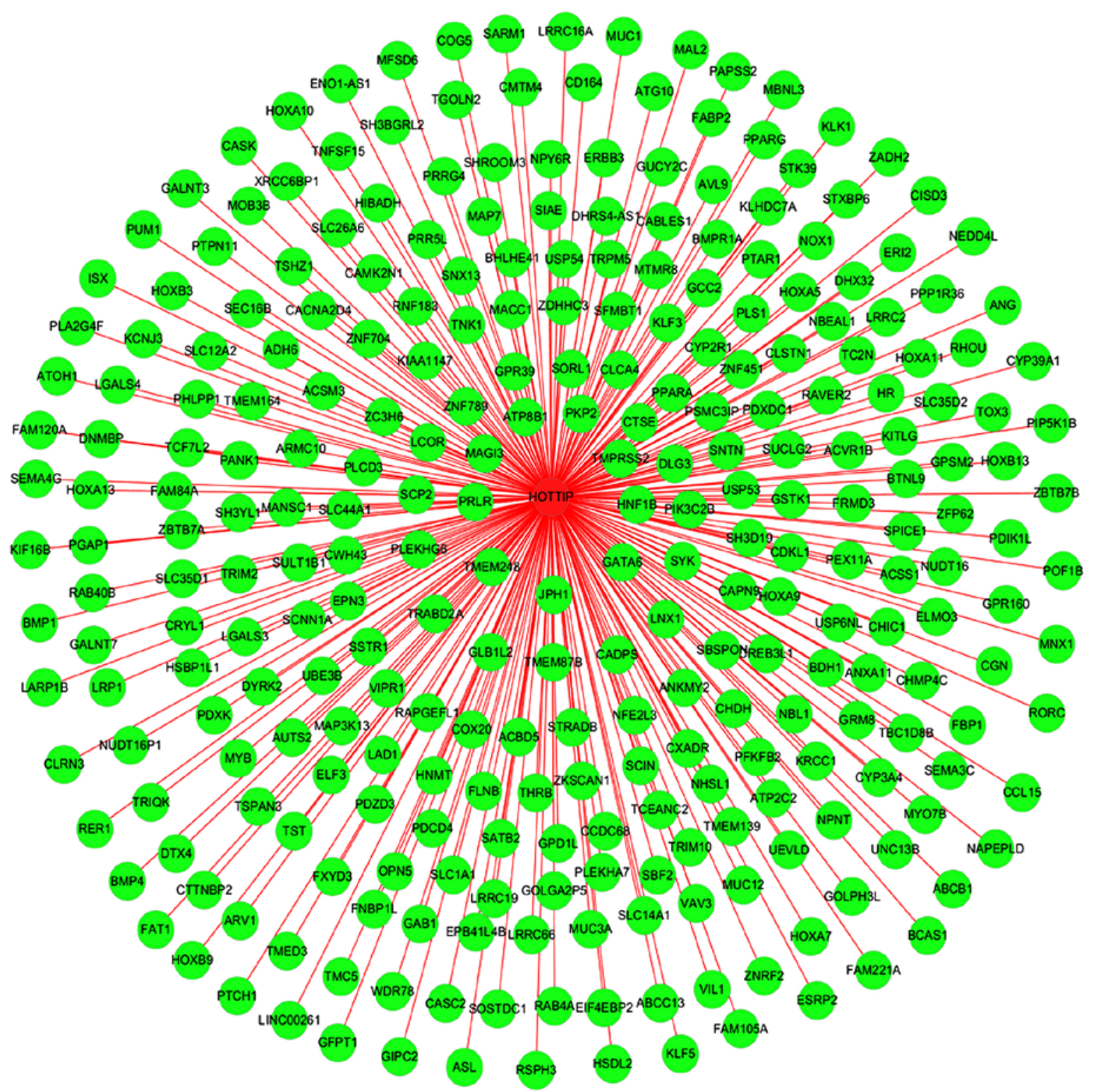

Figure 15. Network analysis between HOTTIP and the potential genes. A gene network of the 287 overlapped genes was constructed. The relationships between HOTTIP and these potential genes were easily observed from this network.

and these genes, we discovered that HOTTIP had a positive correlation with PPARA or SCP2 ( $\mathrm{P}<0.001$, Fig. 17E and F), whereas a negative correlation was found between HOTTIP and PPARG and FABP2 (P>0.05, Fig. 17G and H). Based on the aforementioned results, we hypothesized that HOTTIP may influence the SCP2 expression of PPAR signaling 


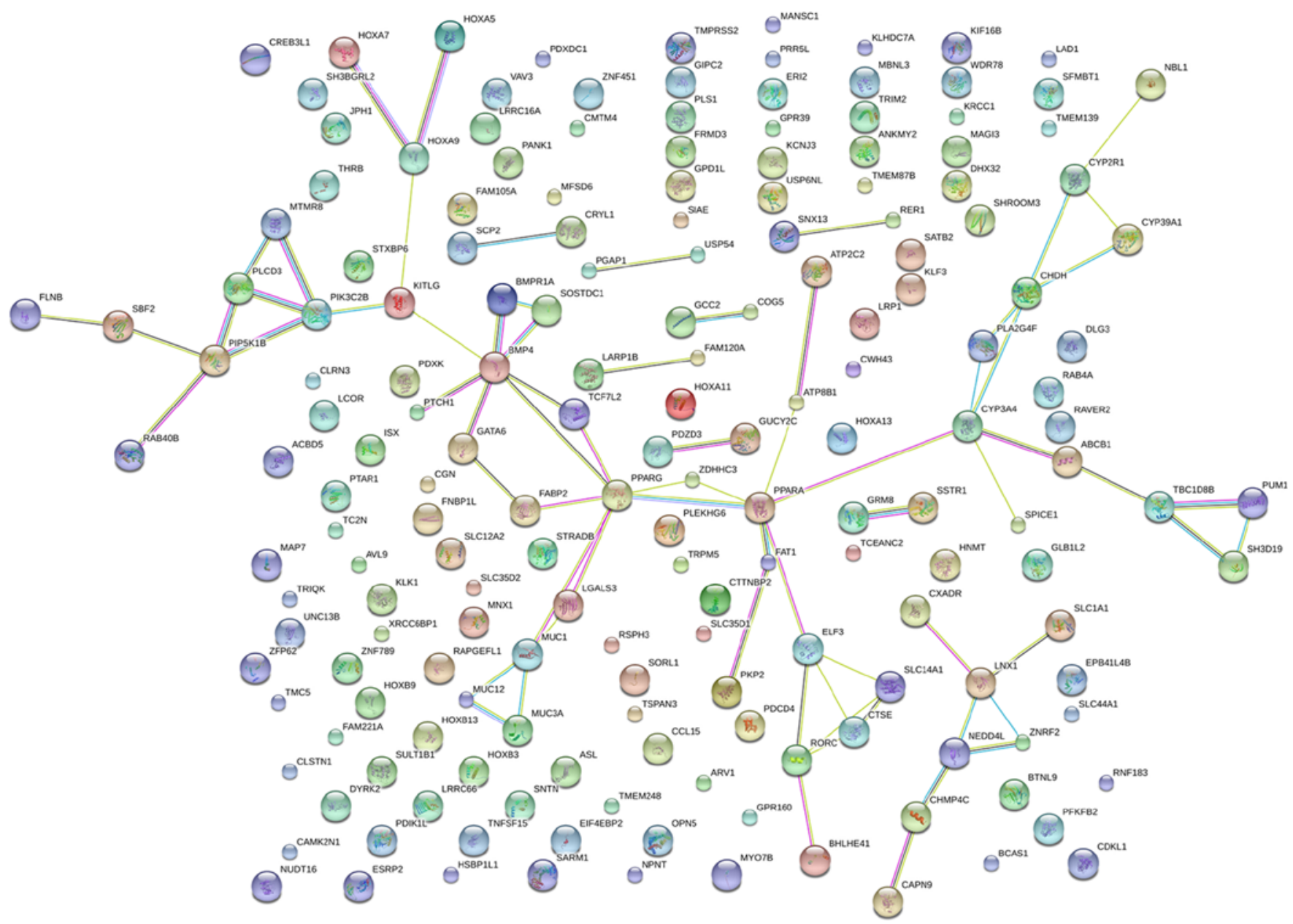

Nodes:

Network nodes represent proteins

splice isoforms or post-

translational modifications are

collapsed, i.e. each node represents

all the proteins produced by a

single, protein-coding genelocus.

\section{Node Size}

a small nodes:

protein of unknown $3 D$ structure

large nodes:

some $3 D$ structure is known or predicted

\section{Node Color}

Ratored nodes:

query proteins and first shell of interactors

(3) whitenodes:

second shell of interactors

\section{Edges:}

Edges represent protein-protein associations

associations are meant to be specific and meaningful, i.e. proteins jointly contribute to a shared function; this does not necessarily mean they are physically binding each other.

\section{Known Interactions}

-- from curated databases

-_- experimentally determined

\section{Predicted Interactions}

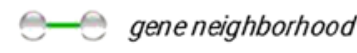

-_- genefusions

--S geneco-occurrence
Others

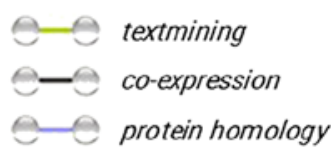

Figure 16. The PPI network of the co-expressed genes. The PPI network was constructed via STRING online and 72 PPI pairs was chosen for further analysis.

pathway to participate in different biological processes of HCC.

\section{Discussion}

Up to now, countless studies have confirmed that lncRNAs could participate in various chemical and biological processes, such as chromosome remodeling, transcription, cancer metastasis and posttranscriptional processing $(66,67)$. Many studies have demonstrated that lncRNAs were related to tumorigenesis and development of HCC through various pathways, including regulation of apoptosis, cell cycle and chemotherapy resistance in HCC tissue or cell lines (68-70). IncRNAs have opened an avenue of cancer genomics.

To date, several studies have investigated the effect and potential mechanism of HOTTIP on HCC. Quagliata et al (71) found that the HOTTIP expression was associated with HCC progression and HOTTIP could be a predictive biomarker in HCC based on the snap-frozen needle HCC biopsies and their matched non-neoplastic counterparts. They also clarified that HOTTIP could directly control the expression of HOXA locus gene by interacting with the WDR5/MLL complex, but 

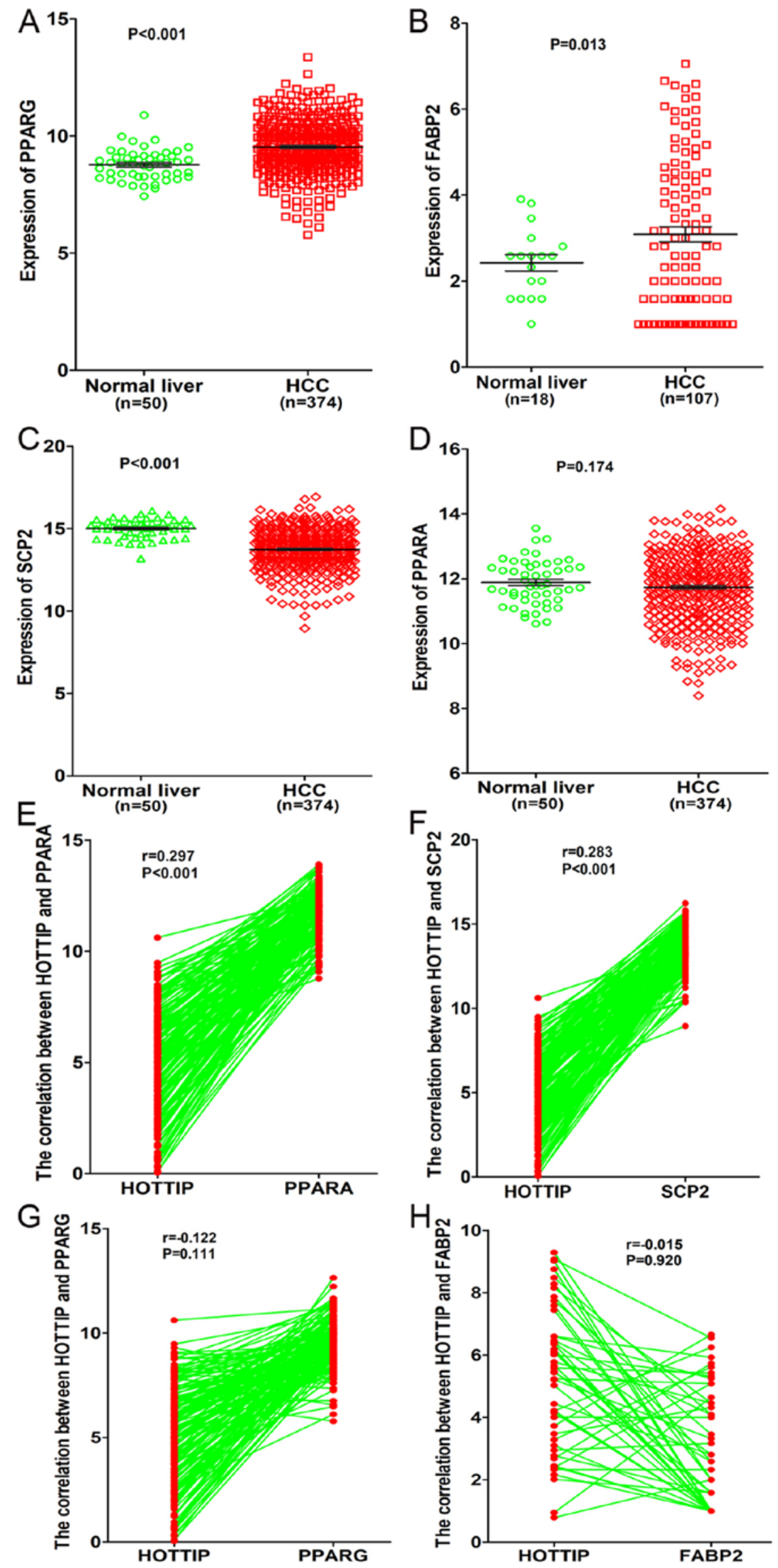

Figure 17. Clinical significance of four related genes (PPARA, PPARG, FABP2, SCP2) in HCC based on TCGA database. (A) Differential expression of PPARG between HCC and non-cancerous liver tissue. (B) Differential expression of FABP2 between HCC and non-cancerous liver tissue. (C) Differential expression of SCP2 between HCC and non-cancerous liver tissue. (D) Differential expression of PPARA between HCC and non-cancerous liver tissue. (E) Positive correlation between HOTTIP and PPARA. (F) Positive correlation between HOTTIP and SCP2. (G) Negative correlation between HOTTIP and PPARG. (H) Negative correlation between HOTTIP and FABP2. 
the specific relationship between HOTTIP and HOX genes is still vague. Tsang et al (45) found that HOTTIP was an oncogenic lncRNA and highly expressed in HCC tissues based on qRT-PCR, and HOTTIP could contribute to hepatocarcinogenesis via targeting tumor suppressive miR-125b, which was verified by luciferase reporter assay and functional analysis. Also, the migratory ability of HCC cells could be inhibited after silencing HOTTIP expression. Ge et al (72), using dual luciferase reporter assays, confirmed that HOTTIP was a significant oncogene in HCC and miR-192/-204-HOTTIP axis was a significant molecular pathway during tumorigenesis of HCC. They also demonstrated the prognostic and potential therapeutic roles of HOTTIP. In comparison, we designed this study using RT-qPCR, meta-analysis and bioinformatics to further investigate the effect of HOTTIP in HCC. Interestingly, we discovered that HOTTIP was a tumorigenic gene and HOTTIP expression was highly expressed in TNM (III +IV), age ( $\geq 60$ ), sex (male), race (white) and cirrhosis (no) compared to that in the control groups. In the present study, ROC curve was applied to evaluate the association between HOTTIP expression and the diagnostic value, and the AUC of HOTTIP indicated the potential diagnostic value of HOTTIP level in HCC. Moreover, this is the first meta-analysis to investigate the expression and diagnostic value of HOTTIP in HCC. As a result, the SMD of the meta-analysis validated the higher expression of HOTTIP in HCC. Furthermore, in the diagnostic meta-analysis, 393 cases from GEO, TCGA, Oncomine and publications were included. The meta-analysis was performed to evaluate the validity of HOTTIP for the detection of HCC. The sensitivity of the HOTTIP assay in the included parts ranged from 70 to $96 \%$, and the specificity of HOTTIP range from 20 to $89 \%$. The combined values of sensitivity (0.88) and specificity (0.59) demonstrated the accuracy of HOTTIP for the detection of HCC. Also, our results clarified that the SROC curve was located near the upper left corner. The AUC was 0.87, which indicated a moderate diagnostic accuracy (73). The PLR and NLR were presented to measure the diagnostic accuracy of HOTTIP. Likelihood ratios $>10$ or $<0.1$ was identified as high accuracy. A PLR value of 2.13 suggested that patients with HCC had an 2.13 -fold higher chance of being HOTTIP assay-positive. In addition, the NLR (0.20) showed that if the HOTTIP result was negative, the chance that this patient has HCC was $20 \%$. Hence, the high diagnostic accuracy in meta-analysis confirmed our results. However, there were some limitations in our meta-analysis. The heterogeneity (high I-square values) is unavoidable, partly because of the opposite results in one probe set of Oncomine. Furthermore, blinding in 4 included databases was not certain, which also contributed to the heterogeneity. In addition, only two publications concerned the prognosis of HOTTIP. In this case, the number of studies restricted the prognostic meta-analysis.

As reported, HOX gene encoded-transcription could regulate cell fate and embryonic development (71). According to GO and KEGG analyses, we found that the most strongly enriched functional terms were embryonic morphogenesis, gland development, transcription factor activity and extrinsic to membrane. Also, the HOTTIP co-expressed genes were significantly related to PPAR signaling pathway. Several studies have demonstrated that PPAR signaling pathway played a vital role in HCC, but no studies were found on
HOTTIP and PPAR signaling pathway $(74,75)$. In the present study, we hypothesized that HOTTIP could play a significant role in HCC via PPAR signaling pathway, but the specific underlying mechanism of HOTTIP in HCC still needs to be investigated with further research. We also investigated the genes from PPAR signaling pathway and the hub genes from PPI. In addition, we hypothesized that HOTTIP may influence the SCP2 expression of PPAR signaling pathway to participate in different biological processes of HCC. To verify our hypothesis, we intend to perform various experiments, including proliferation, invasion and metastasis assays, chicken embryochorioallantoic membrane and nude mouse models. The clinical significance and the molecular mechanism of HOTTIP on the biological function of HCC will be investigated from the perspectives of molecule, cell, tissue and animal. However, the circulating HOTTIP in HCC patients has higher clinical value in evaluating the real diagnostic potential of HOTTIP than HOTTIP in tissues. We also intend to perform in-depth exploration on the circulating HOTTIP in HCC patients in the future. Focusing on the new insight of HOTTIP, this study aimed to provide a new biomarker or therapeutic target for HCC.

\section{Acknowledgements}

This study was supported by the Fund of National Natural Science Foundation of China (NSFC81560386) and the Fund of Guangxi Medical University Training Program for Distinguished Young Scholars (2017). The authors acknowledge the data provided by the TCGA database.

\section{References}

1. Li C, Miao R, Liu S, Wan Y, Zhang S, Deng Y, Bi J, Qu K, Zhang J and Liu C: Down-regulation of miR-146b-5p by long noncoding RNA MALAT1 in hepatocellular carcinoma promotes cancer growth and metastasis. Oncotarget 8: 28683-28695, 2017.

2. Lu PH, Chen MB, Liu YY, Wu MH, Li WT, Wei MX, Liu CY and Qin SK: Identification of sphingosine kinase 1 (SphK1) as a primary target of icaritin in hepatocellular carcinoma cells. Oncotarget 8: 22800-22810, 2017.

3. He R, Gao L, Ma J, Peng Z, Zhou S, Yang L, Feng Z, Dang Y and Chen G: The essential role of MTDH in the progression of HCC: A study with immunohistochemistry, TCGA, meta-analysis and in vitro investigation. Am J Transl Res 9: 1561-1579, 2017.

4. Mo Z, Zheng S, Lv Z, Zhuang Y, Lan X, Wang F, Lu X, Zhao Y and Zhou S: Senescence marker protein 30 (SMP30) serves as a potential prognostic indicator in hepatocellular carcinoma. Sci Rep 6: 39376, 2016.

5. Huang WT, Wang HL, Yang H, Ren FH, Luo YH, Huang CQ Liang YY, Liang HW, Chen G and Dang YW: Lower expressed miR-198 and its potential targets in hepatocellular carcinoma: A clinicopathological and in silico study. Onco Targets Ther 9: 5163-5180, 2016.

6. Torre LA, Bray F, Siegel RL, Ferlay J, Lortet-Tieulent J and Jemal A: Global cancer statistics, 2012. CA Cancer J Clin 65: 87-108, 2015.

7. Xu Y, Qi Y, Luo J, Yang J, Xie Q, Deng C, Su N, Wei W, Shi D, $\mathrm{Xu} F$, et al: Hepatitis B Virus $\mathrm{X}$ protein stimulates proliferation, wound closure and inhibits apoptosis of $\mathrm{HuH}-7$ cells via $\mathrm{CDC} 42$. Int J Mol Sci 18: 18, 2017

8. Yu C, Cao Q, Chen P, Yang S, Gong X, Deng M, Ruan B and Li L: Tissue transglutaminase 2 exerts a tumor-promoting role in hepatitis B virus-related hepatocellular carcinoma. Tumour Biol 37: 16269-16274, 2016.

9. Gong X, Wei W, Chen L, Xia Z and Yu C: Comprehensive analysis of long non-coding RNA expression profiles in hepatitis B virusrelated hepatocellular carcinoma. Oncotarget 7: 42422-42430, 2016. 
10. Dengler M, Staufer K, Huber H, Stauber R, Bantel H, Weiss KH, Starlinger P, Pock H, Klöters-Plachky P, Gotthardt DN, et al: Soluble Axl is an accurate biomarker of cirrhosis and hepatocellular carcinoma development: Results from a large scale multicenter analysis. Oncotarget 8: 46234-46248, 2017.

11. Ye Q, Qian BX, Yin WL, Wang FM and Han T: Association between the HFE C282Y, H63D polymorphisms and the risks of non-alcoholic fatty liver disease, liver cirrhosis and hepatocellular carcinoma: An updated systematic review and meta-analysis of 5,758 cases and 14,741 controls. PLoS One 11: e0163423, 2016.

12. Joshi K, Kohli A, Manch R and Gish R: Alcoholic liver disease: High risk or low risk for developing hepatocellular carcinoma? Clin Liver Dis 20: 563-580, 2016.

13. Fairman J, Liu KH and Menne S: Prevention of liver tumor formation in woodchucks with established hepatocellular carcinoma by treatment with cationic liposome-DNA complexes. BMC Cancer 17: 172, 2017.

14. Hectors SJ, Wagner M, Bane O, Besa C, Lewis S, Remark R, Chen N, Fiel MI, Zhu H, Gnjatic S, et al: Quantification of hepatocellular carcinoma heterogeneity with multiparametric magnetic resonance imaging. Sci Rep 7: 2452, 2017.

15. Xie X, Pan J, Wei L, Wu S, Hou H, Li X and Chen W: Gene expression profiling of microRNAs associated with UCA1 in bladder cancer cells. Int J Oncol 48: 1617-1627, 2016.

16. Sun XJ, Wang Q, Guo B, Liu XY and Wang B: Identification of skin-related lncRNAs as potential biomarkers that involved in Wnt pathways in keloids. Oncotarget 8: 34236-34244, 2017.

17. Ma G, Tang M, Wu Y, Xu X, Pan F and Xu R: LncRNAs and miRNAs: Potential biomarkers and therapeutic targets for prostate cancer. Am J Transl Res 8: 5141-5150, 2016.

18. Wilusz JE: Long noncoding RNAs: Re-writing dogmas of RNA processing and stability. Biochim Biophys Acta 1859: 128-138, 2016.

19. Yuan X, Wang J, Tang X, Li Y, Xia P and Gao X: Berberine ameliorates nonalcoholic fatty liver disease by a global modulation of hepatic mRNA and lncRNA expression profiles. J Transl Med 13: 24, 2015.

20. Wei Y and Niu B: Role of MALAT1 as a prognostic factor for survival in various cancers: A systematic review of the literature with meta-analysis. Dis Markers 2015: 164635, 2015.

21. Wei Y and Zhang X: Transcriptome analysis of distinct long non-coding RNA transcriptional fingerprints in lung adenocarcinoma and squamous cell carcinoma. Tumour Biol 37: 16275-16285, 2016.

22. Li Y, Li W, Liang B, Li L, Wang L, Huang H, Guo S, Wang Y, He Y, Chen L, et al: Identification of cancer risk lncRNAs and cancer risk pathways regulated by cancer risk lncRNAs based on genome sequencing data in human cancers. Sci Rep 6: 39294, 2016.

23. Li SP, Xu HX, Yu Y, He JD, Wang Z, Xu YJ, Wang CY, Zhang HM, Zhang RX, Zhang JJ, et al: LncRNA HULC enhances epithelial-mesenchymal transition to promote tumorigenesis and metastasis of hepatocellular carcinoma via the miR-200a-3p/ ZEB1 signaling pathway. Oncotarget 7: 42431-42446, 2016.

24. Huang ZL, Chen RP, Zhou XT, Zhan HL, Hu MM, Liu B, Wu GD and Wu LF: Long non-coding RNA MEG3 induces cell apoptosis in esophageal cancer through endoplasmic reticulum stress. Oncol Rep 37: 3093-3099, 2017.

25. Zhang Y, Zhang Q, Zhang M, Yuan M, Wang Z, Zhang J, Zhou X, Zhang Y, Lin F, Na H, et al: DC - SIGNR by influencing the IncRNA HNRNPKP2 upregulates the expression of CXCR4 in gastric cancer liver metastasis. Mol Cancer 16: 78, 2017.

26. Li J, Zhang Z, Xiong L, Guo C, Jiang T, Zeng L, Li G and Wang J: SNHG1 lncRNA negatively regulates miR-199a-3p to enhance CDK7 expression and promote cell proliferation in prostate cancer. Biochem Biophys Res Commun 487: 146-152, 2017.

27. Xue F, Liu Y, Chu H, Wen Y, Yan L, Tang Q, Xiao E, Zhang D and Zhang H: eIF5A2 is an alternative pathway for cell proliferation in cetuximab-treated epithelial hepatocellular carcinoma. Am J Transl Res 8: 4670-4681, 2016.

28. Deng LL, Chi YY, Liu L, Huang NS, Wang L and Wu J: LINC00978 predicts poor prognosis in breast cancer patients. Sci Rep 6: 37936, 2016.

29. Guo S, Chen W, Luo Y, Ren F, Zhong T, Rong M, Dang Y, Feng Z and Chen G: Clinical implication of long non-coding RNA NEAT1 expression in hepatocellular carcinoma patients. Int J Clin Exp Pathol 8: 5395-5402, 2015.

30. Zhu P, Wang Y, Wu J, Huang G, Liu B, Ye B, Du Y, Gao G, Tian Y, He L, et al: LncBRM initiates YAP1 signalling activation to drive self-renewal of liver cancer stem cells. Nat Commun 7: 13608, 2016.
31. Cao C, Sun J, Zhang D, Guo X, Xie L, Li X, Wu D and Liu L: The long intergenic noncoding RNA UFC1, a target of MicroRNA 34a, interacts with the mRNA stabilizing protein HuR to increase levels of beta-catenin in HCC cells. Gastroenterology 148: 415-426 e418, 2015.

32. Zhou M, Zhang XY and Yu X: Overexpression of the long non-coding RNA SPRY4-IT1 promotes tumor cell proliferation and invasion by activating EZH2 in hepatocellular carcinoma. Biomed Pharmacother 85: 348-354, 2017.

33. Xu LM, Chen L, Li F, Zhang R, Li Z-Y, Chen F-F and Jiang X-D: Over-expression of the long non-coding RNA HOTTIP inhibits glioma cell growth by BRE. J Exp Clin Cancer Res 35: 162, 2016.

34. Zhang X, Tang W, Li R, He R, Gan T, Luo Y, Chen G and Rong M: Downregulation of microRNA-132 indicates progression in hepatocellular carcinoma. Exp Ther Med 12: 2095-2101, 2016.

35. Jin W, Chen L, Cai X, Zhang Y, Zhang J, Ma D, Cai X, Fu T, Yu Z, Yu F, et al: Long non-coding RNA TUC338 is functionally involved in sorafenib-sensitized hepatocarcinoma cells by targeting RASAL1. Oncol Rep 37: 273-280, 2017.

36. Yin X, Zheng SS, Zhang L, Xie XY, Wang Y, Zhang BH, Wu W, Qiu S and Ren ZG: Identification of long noncoding RNA expression profile in oxaliplatin-resistant hepatocellular carcinoma cells. Gene 596: 53-88, 2017.

37. Lin L, Zhang YD, Chen ZY, Chen Y and Ren CP: The clinicopathological significance of miR-149 and PARP-2 in hepatocellular carcinoma and their roles in chemo/radiotherapy. Tumour Biol 37: 12339-12346, 2016.

38. Colombo T, Farina L, Macino G and Paci P: PVT1: A rising star among oncogenic long noncoding RNAs. BioMed Res Int 2015: 304208, 2015.

39. Liu FT, Xue QZ, Zhang Y, Hao TF, Luo HL and Zhu PQ: Long non-coding RNA HOXA transcript at the distal tip as a putative biomarker of metastasis and prognosis: A meta-analysis. Clin Lab 62: 2091-2098, 2016.

40. Yang Y, Qian J, Xiang Y, Chen Y and Qu J: The prognostic value of long noncoding RNA HOTTIP on clinical outcomes in breast cancer. Oncotarget 8: 6833-6844, 2017.

41. Chen Z, He A, Wang D, Liu Y and Huang W: Long noncoding RNA HOTTIP as a novel predictor of lymph node metastasis and survival in human cancer: A systematic review and meta-analysis. Oncotarget 8: 14126-14132, 2017.

42. Chen X, Han H, Li Y, Zhang Q, Mo K and Chen S: Upregulation of long noncoding RNA HOTTIP promotes metastasis of esophageal squamous cell carcinoma via induction of EMT. Oncotarget 7: 84480-84485, 2016.

43. Li Z, Zhao L and Wang Q: Overexpression of long non-coding RNA HOTTIP increases chemoresistance of osteosarcoma cell by activating the Wnt/ $\beta$-catenin pathway. Am J Transl Res 8: 2385-2393, 2016.

44. Ye H, Liu K and Qian K: Overexpression of long noncoding RNA HOTTIP promotes tumor invasion and predicts poor prognosis in gastric cancer. Onco Targets Ther 9: 2081-2088, 2016.

45. Tsang FH, Au SL, Wei L, Fan DN, Lee JM, Wong CC, Ng IO and Wong CM: Long non-coding RNA HOTTIP is frequently up-regulated in hepatocellular carcinoma and is targeted by tumour suppressive miR-125b. Liver Int 35: 1597-1606, 2015.

46. Xu X, Wang X, Fu B, Meng L and Lang B: Differentially expressed genes and microRNAs in bladder carcinoma cell line 5637 and T24 detected by RNA sequencing. Int J Clin Exp Pathol 8: 12678-12687, 2015.

47. Subramanian Y, Kaliyappan K and Ramakrishnan KS: Facile hydrothermal synthesis and characterization of $\mathrm{Co}_{2} \mathrm{GeO}_{4} /$ r-GO@C ternary nanocomposite as negative electrode for $\mathrm{Li}$-ion batteries. J Colloid Interface Sci 498: 76-84, 2017.

48. Fu L, Xu Y, Hou Y, Qi X, Zhou L, Liu H, Luan Y, Jing L, Miao Y, Zhao S, et al: Proteomic analysis indicates that mitochondrial energy metabolism in skeletal muscle tissue is negatively correlated with feed efficiency in pigs. Sci Rep 7: 45291, 2017.

49. Sang Y, Zhou F, Wang D, Bi X, Liu X, Hao Z, Li Q and Zhang W: Up-regulation of long non-coding HOTTIP functions as an oncogene by regulating HOXA13 in non-small cell lung cancer. Am J Transl Res 8: 2022-2032, 2016.

50. Dai J, Wu H, Zhang Y, Gao K, Hu G, Guo Y, Lin C and Li X: Negative feedback between TAp63 and Mir-133b mediates colorectal cancer suppression. Oncotarget 7: 87147-87160, 2016.

51. Wu H, Zhou J, Zeng C, Wu D, Mu Z, Chen B, Xie Y, Ye Y and Liu J: Curcumin increases exosomal TCF21 thus suppressing exosome-induced lung cancer. Oncotarget 7: 87081-87090, 2016. 
52. Bornstein S, Schmidt M, Choonoo G, Levin T, Gray J, Thomas CR Jr, Wong M and McWeeney S: IL-10 and integrin signaling pathways are associated with head and neck cancer progression. BMC Genomics 17: 38, 2016.

53. Zeng JH, Xiong DD, Pang YY, Zhang Y, Tang RX, Luo DZ and Chen G: Identification of molecular targets for esophageal carcinoma diagnosis using miRNA-seq and RNA-seq data from The Cancer Genome Atlas: A study of 187 cases. Oncotarget 8 : 35681-35699, 2017.

54. Rhodes DR, Kalyana-Sundaram S, Mahavisno V, Varambally R, Yu J, Briggs BB, Barrette TR, Anstet MJ, Kincead-Beal C, Kulkarni P, et al: Oncomine 3.0: Genes, pathways, and networks in a collection of 18,000 cancer gene expression profiles. Neoplasia 9: 166-180, 2007.

55. Adler P, Kolde R, Kull M, Tkachenko A, Peterson H, Reimand J and Vilo J: Mining for coexpression across hundreds of datasets using novel rank aggregation and visualization methods. Genome Biol 10: R139, 2009.

56. Tang W, Liao Z and Zou Q: Which statistical significance test best detects oncomiRNAs in cancer tissues? An exploratory analysis. Oncotarget 7: 85613-85623, 2016

57. Li CQ, Huang GW, Wu ZY, Xu YJ, Li XC, Xue YJ, Zhu Y, Zhao JM, Li M, Zhang J, et al: Integrative analyses of transcriptome sequencing identify novel functional lncRNAs in esophageal squamous cell carcinoma. Oncogenesis 6: e297, 2017.

58. Dinh TA, Vitucci EC, Wauthier E, Graham RP, Pitman WA Oikawa T, Chen M, Silva GO, Greene KG, Torbenson MS, et al: Comprehensive analysis of The Cancer Genome Atlas reveals a unique gene and non-coding RNA signature of fibrolamellar carcinoma. Sci Rep 7: 44653, 2017.

59. Seiler R, Black PC, Thalmann G, Stenzl A and Todenhöfer T: Is The Cancer Genome Atlas (TCGA) bladder cancer cohort representative of invasive bladder cancer? Urol Oncol 35: 458 e1-458.e7, 2017.

60. Gao H, Wang $\mathrm{H}$ and Yang W: Identification of key genes and construction of microRNA-mRNA regulatory networks in multiple myeloma by integrated multiple GEO datasets using bioinformatics analysis. Int J Hematol 106: 99-107, 2017.

61. Tan W, Song Y, Mo C, Jiang S and Wang Z: Analysis of gene expression profile microarray data in complex regional pain syndrome. Mol Med Rep 16: 3371-3378, 2017.

62. Mirsafian H, Ripen AM, Leong WM, Chear CT, Bin Mohamad S and Merican AF: Transcriptome profiling of monocytes from XLA patients revealed the innate immune function dysregulation due to the BTK gene expression deficiency. Sci Rep 7: 6836, 2017.

63. Zhao Z, Bai J, Wu A, Wang Y, Zhang J, Wang Z, Li Y, Xu J and Li X: Co-LncRNA: Investigating the lncRNA combinatorial effects in GO annotations and KEGG pathways based on human RNA-Seq data. Database (Oxford): Sep 10, 2015 (Epub ahead of print). doi: 10.1093/database/bav082.
64. Franceschini A, Szklarczyk D, Frankild S, Kuhn M, Simonovic M, Roth A, Lin J, Minguez P, Bork P, von Mering C, et al: STRING v9.1: Protein-protein interaction networks, with increased coverage and integration. Nucleic Acids Res 41D: D808-D815, 2013.

65. Zamora J, Abraira V, Muriel A, Khan K and Coomarasamy A: Meta-DiSc: A software for meta-analysis of test accuracy data. BMC Med Res Methodol 6: 31, 2006.

66. Shi X, Sun M, Liu H, Yao Y and Song Y: Long non-coding RNAs: A new frontier in the study of human diseases. Cancer Lett 339: 159-166, 2013.

67. Xiong DD, Feng ZB, Cen WL, Zeng JJ, Liang L, Tang RX, Gan XN, Liang HW, Li ZY, Chen G, et al: The clinical value of lncRNA NEAT1 in digestive system malignancies: A comprehensive investigation based on 57 microarray and RNA-seq datasets. Oncotarget 8: 17665-17683, 2017.

68. Lu S, Zhou J, Sun Y, Li N, Miao M, Jiao B and Chen H: The noncoding RNA HOXD-AS1 is a critical regulator of the metastasis and apoptosis phenotype in human hepatocellular carcinoma. Mol Cancer 16: 125, 2017.

69. Xu LC, Chen QN, Liu XQ, Wang XM, Chang QM, Pan Q, Wang L and Wang YL: Up-regulation of LINC00161 correlates with tumor migration and invasion and poor prognosis of patients with hepatocellular carcinoma. Oncotarget 8: 56168-56173, 2017.

70. Wang Y, Hu Y, Wu G, Yang Y, Tang Y, Zhang W, Wang K, Liu Y, Wang $X$ and Li T: Long noncoding RNA PCAT-14 induces proliferation and invasion by hepatocellular carcinoma cells by inducing methylation of miR-372. Oncotarget 8: 34429-34441, 2017.

71. Quagliata L, Matter MS, Piscuoglio S, Arabi L, Ruiz C, Procino A, Kovac M, Moretti F, Makowska Z, Boldanova T, et al: Long noncoding RNA HOTTIP/HOXA13 expression is associated with disease progression and predicts outcome in hepatocellular carcinoma patients. Hepatology 59: 911-923, 2014.

72. Ge Y, Yan X, Jin Y, Yang X, Yu X, Zhou L, Han S, Yuan Q and Yang M: MiRNA-192 [corrected] and miRNA-204 directly suppress lncRNA HOTTIP and interrupt GLS1-mediated glutaminolysis in hepatocellular carcinoma. PLoS Genet 11: e1005726, 2015.

73. Swets JA: Measuring the accuracy of diagnostic systems. Science 240: 1285-1293, 1988.

74. Lu G, Zhang G, Zheng X, Zeng Y, Xu Z, Zeng W and Wang K: c9, t11- conjugated linoleic acid induces HCC cell apoptosis and correlation with PPAR- $\gamma$ signaling pathway. Am J Transl Res 7: 2752-2763, 2015.

75. Li J, Huang Q, Long X, Zhang J, Huang X, Aa J, Yang H, Chen Z and Xing J: CD147 reprograms fatty acid metabolism in hepatocellular carcinoma cells through Akt/mTOR/SREBP1c and P38/ PPAR $\alpha$ pathways. J Hepatol 63: 1378-1389, 2015. 